\title{
Assessment of the influence of the elastic properties of rail vehicle suspensions on safety, ride quality and track fatigue
}

\author{
B. Suarez, J. M. Mera, M. L. Martinez and J. A. Chover
}

A sensitivity analysis has been performed to assess the influence of the elastic properties of railway vehicle suspensions on the vehicle dynamic behaviour. To do this, 144 dynamic simulations were performed modifying, one at a time, the stiffness and damping coefficients, of the primary and secondary suspensions. Three values were assigned to each parameter, corresponding to the percentiles 10,50 and 90 of a data set stored in a database of railway vehicles.After processing the results of these simulations, the analyzed parameters were sorted by increasing influence. It was also found which of these parameters could be estimated with a lesser degree of accuracy in future simulations without appreciably affecting the simulation results. In general terms, it was concluded that the highest influences were found for the longitudinal stiffness and the lateral stiffness of the primary suspension, and the lowest influences for the vertical stiffness and the vertical damping of the primary suspension, with the parameters of the secondary suspension showing intermediate influences between them.

This is an electronic version of an article published in Vehicle System Dynamics,

Vol. 51, No. 2, 2013, pp. 280-300.

VEHICLE SYSTEM DYNAMICS is available online at:

http://www.tandfonline.com/doi/abs/10.1080/00423114.2012.725852

DOI: $10.1080 / 00423114.2012 .725852$

When citing this work, please refer to the published paper:

B. Suarez, J. M. Mera, M. L. Martinez and J. A. Chover, Assessment of the influence of the elastic properties of rail vehicle suspensions on safety, ride quality and track fatigue. Vehicle System Dynamics, Vol. 51, pp. 280-300. 


\title{
Assessment of the influence of the elastic properties of rail vehicle suspensions on safety, ride quality and track fatigue
}

\author{
Berta Suarez ${ }^{1}$, Jose Manuel Mera, Maria Luisa Martinez, Jose Antonio Chover \\ Departamento de Ingeniería Mecánica y Fabricación. Universidad Politécnica de Madrid. \\ ETSI Industriales (CITEF), C/ Jose Gutierrez Abascal, 2, ES-28006 Madrid, SPAIN
}

\begin{abstract}
A sensitivity analysis has been performed to assess the influence of the elastic properties of railway vehicle suspensions on the vehicle dynamic behaviour. To do this, 144 dynamic simulations were performed modifying, one at a time, the stiffness and damping coefficients, of the primary and secondary suspensions. Three values were assigned to each parameter, corresponding to the percentiles 10,50 and 90 of a data set stored in a database of railway vehicles.

After processing the results of these simulations, the analyzed parameters were sorted by increasing influence. It was also found which of these parameters could be estimated with a lesser degree of accuracy in future simulations without appreciably affecting the simulation results. In general terms, it was concluded that the highest influences were found for the longitudinal stiffness and the lateral stiffness of the primary suspension, and the lowest influences for the vertical stiffness and the vertical damping of the primary suspension, with the parameters of the secondary suspension showing intermediate influences between them.
\end{abstract}

Keywords: railway dynamics, sensitivity analysis, dynamic behaviour, stiffness, damping, primary suspension, secondary suspension, safety, track fatigue, ride quality, EN 14363 standard, UIC 518 leaflet

\section{INTRODUCTION}

Usually, when building any model to simulate the dynamic behaviour of a railway vehicle, not all the required data are known. Sometimes, the value of some vehicle parameters has a related uncertainty due to the manufacturing process or even to component degradation during service. Other times, the value of these parameters is completely unknown. This usually happens when the components to be modelled were manufactured by third parties or even when the vehicle to be analyzed was manufactured many years ago.

In this work, a sensitivity study was performed in order to find the degree of accuracy required in the definition of each vehicle parameter (1). In particular, it was intended to analyze the sensitivity of the vehicle dynamic behaviour to the elastic properties of the primary and secondary suspensions, under different running conditions. This study was complemented by two others, where the influences of the inertial properties of the main bodies of the vehicle (2), as well as that of the rolling features, were also analyzed (3).

\footnotetext{
${ }^{1}$ Corresponding autor: Berta Suarez, e-mail: citef-bsuarez@etsii.upm.es, Postal address: ETSI Industriales (CITEF), C/Jose Gutierrez Abascal, 2, ES-28006 Madrid, SPAIN
} 
Both the simulation models and the working methodology used in this work are described in detail in a previous work (2). Nevertheless, they are summarized here, in paragraph 3 , in order to provide some continuity to the present text.

To consider the influence of the model uncertainties on the vehicle dynamics, a probabilistic approach should be used, as it would predict how the uncertainty of input parameters would be propagated to the model output. A probabilistic method commonly used in such situations is the Monte Carlo simulation, but it requires extremely high computation costs when many uncertain input parameters have to be considered. Other more effective probabilistic methods are sometimes used as, for example, the combination of Monte Carlo simulation technique and the design of experiments theory (4) or the generalized polynomial chaos theory (5), though they are also time consuming.

Despite their high computational cost, probabilistic methods should be used whenever quantitative results are required. However, for preliminary research studies, where qualitative results showing the relative importance of the parameters being considered would suffice, simpler methods could be applied. The simplest method consists in modifying input parameters one at a time, thus neglecting any possible relationship that could exist between them. These simplifications make the precision of this method lower than the precision of the previously mentioned probabilistic methods. However, it is very helpful due to its simplicity, which allows analyzing many parameters with a relatively low computational cost, in comparison with the probabilistic methods.

As stated before, the work here exposed is part of a wider study, where the influences of 24 input parameters of the vehicle model were considered: 12 inertial properties of the vehicle bodies, 8 elastic properties of the suspension components and 4 parameters related with the rolling contact. For each parameter, several track layouts and vehicle speeds were also considered. Due to the large number of uncertain input parameters and external conditions to be considered, and having in mind the above mentioned considerations, the simplest approach was chosen for this study. Therefore, the input parameters were modified one at a time, with just three values in each variation, even for parameters with large variation ranges, so assuming that the output quantities are smooth functions of the input parameters.

In view of the above mentioned limiting conditions, the present work could be considered as a starting point, as it would provide a qualitative idea about which influence quantities need to be addressed with particular care when performing simulations addressing a specific problem. From the results obtained, the number of parameters to be considered to undertake in the future a probabilistic approach could be reduced. This way, quantitative and more accurate results could be obtained with a considerable lower computational cost than considering all the uncertain input parameters.

To undertake this work, a reference vehicle model was defined. From this reference model, the values of the elastic properties to be analyzed were independently modified, one at a time. In principle, the elastic properties to be considered, both for the primary and secondary suspensions, are the longitudinal, the lateral and the vertical stiffness and damping. However, the longitudinal and the lateral damping of the primary suspension, as well as the longitudinal stiffness and damping of the secondary suspension were discarded for this analysis. This decision was taken due to the scarcity of data available for these parameters, which would lead to unrealistic estimations for both their median values and their variation ranges.

Both the reference model characteristics and the variation ranges assigned to each parameter (6), (7), were assessed from the information stored in a database of railway vehicles (8), which was specifically built for this purpose. 
A methodology was also developed, to allow a systematic analysis of vehicle dynamic response, thus avoiding to focus on extremely specific cases. With this aim, entirely generic simulation scenarios were defined. In the same way, a systematic statistical treatment was carried out on the simulation results. To define the track layouts and the track qualities to be used in the simulations, the specifications stated in the UIC-518 leaflet (9) and in the European standard EN-14363 (10), generally used for railway vehicle authorisation by means of on-track tests, were applied in a virtual environment. The same specifications were also used to post-process the results of the simulations. This procedure was chosen for this project because it is well established, supported by many years of experience, and allows the assessment of vehicle dynamics by means of only a few indexes. These indexes can be compared with some limit values, defined in these standards, in order to find whether the vehicle behaviour is suitable or not from a safety, track fatigue and ride quality point of view.

This methodology allows the identification of the critical parameters of the simulation models. It also allowed the identification of those elastic properties which could be estimated with lesser accuracy due to their low impact on the accuracy of the simulation results.

\section{BACKGROUND}

Sensitivity analyses which directly involve the parameters of the two stages of the vehicle suspension are by far the most common, especially those regarding the stiffness of primary and secondary suspensions. In this context, this paragraph shows a literature review of various publications presenting the results of several dynamic simulations in which the value of some parameters related with the elastic properties of the primary and the secondary suspensions were modified. The parameters analyzed in each reference are listed below. These bibliographic references were classified according to the type of dynamic study described in each of them. Three types of studies were considered: safety, track fatigue and ride quality. The former, in turn, was also divided into linear stability, nonlinear stability and derailment risk studies.

A review of the state of the art in suspension component modelling can be found in (11), (12) and (13). Before presenting the above mentioned literature review, it is worth mentioning some recent works including a thorough description of advanced simulation techniques used to model non linear suspension components, such as the air springs commonly used in the secondary suspension of passenger vehicles (14), (15), (16), (17), the rubber springs used in some primary suspensions (18), (19), or even the link suspensions still used in some freight wagons (20), (21). Despite the interest of these modelling techniques, they are out of the scope of the present study, as the amount of numerical data related to nonlinear suspension models is too small to perform a statistical analysis such as the one made here with linear suspension models and briefly described in paragraph 3.3.

\subsection{SAFETY STUDIES}

Table 1, Table 2 and Table 3 respectively gather some bibliographic references on linear stability, non-linear stability and derailment risk studies. 


\begin{tabular}{|c|c|c|c|c|}
\hline Reference & Modified parameter ${ }^{1}$ & $\begin{array}{l}\text { Method of } \\
\text { analysis }^{2}\end{array}$ & $\begin{array}{l}\text { Vehicle } \\
\text { model }^{3}\end{array}$ & Variables analyzed ${ }^{4}$ \\
\hline (22) & $\mathrm{k} 1 \mathrm{x} / \mathrm{y}, \mathrm{d} 1 \mathrm{x} / \mathrm{y}, \mathrm{k} 2 \mathrm{x} / \mathrm{y}$ & Own formulation & Car & $\mathrm{V}_{\mathrm{C}}$ \\
\hline (23) & $k 2 x / y / z / a / y, d 2 y / z$ & MBS (ADAMS) & Car & eigenvalues \\
\hline (24) & $\mathrm{k} 1 \mathrm{z}, \mathrm{k} 2 \mathrm{z}, \mathrm{kw}, \mathrm{dw}$ & FEM/MBS & 1/4 Car & $\mathrm{V}_{\mathrm{C}}$ \\
\hline (25) & $\mathrm{k} 1 \mathrm{y} / \mathrm{y}$ & Own formulation & Wheelset & $\mathrm{V}_{\mathrm{C}}$ \\
\hline (25) & k1y & Own formulation & Bogie & $\mathrm{V}_{\mathrm{C}}$ \\
\hline (26) & $\mathrm{k} 1 \mathrm{~b} / \mathrm{s}$ & Own formulation & Bogie & $\mathrm{V}_{\mathrm{C}}$ \\
\hline (27) & $\mathrm{k} 1 \mathrm{~b}, \mathrm{~d} 1 \mathrm{x}$ & Own formulation & Bogie & $\mathrm{V}_{\mathrm{C}}$ \\
\hline (28) & $k 1 x / y, d 1 y, k 2 y, d 2 y / y$ & Own formulation & Car & $\mathrm{V}_{\mathrm{C}}$ \\
\hline (29) & $\mathrm{k} 1 \mathrm{~b} / \mathrm{s}$ & MBS (SIDIVE) & Bogie & eigenvalues \\
\hline (29) & $k 1 x / y, k 2 x / y, d 2 y$ & MBS (SIDIVE) & Car & $\mathrm{V}_{\mathrm{C}}$ \\
\hline$(30)$ & $\mathrm{k} 1 \mathrm{x} / \mathrm{y} / \mathrm{z}, \mathrm{d} 1 \mathrm{x} / \mathrm{y} / \mathrm{z}, \mathrm{k} 2 \mathrm{y} / \mathrm{z}, \mathrm{d} 2 \mathrm{y} / \mathrm{z}$ & MBS (A'GEM) & Car & eigenvalues, $V_{c}$ \\
\hline (31) & $\mathrm{k} 2 \mathrm{x}$ & Own formulation & NA Train & $\mathrm{V}_{\mathrm{C}}$ \\
\hline (32) & $\mathrm{k} 1 \mathrm{x} / \mathrm{y} / \mathrm{z}, \mathrm{d} 1 \mathrm{z}, \mathrm{d} 2 \mathrm{x} / \mathrm{y}$ & Own formulation & Bogie & $\mathrm{V}_{\mathrm{C}}$ \\
\hline (33) & $\mathrm{k} 1 \mathrm{x} / \mathrm{y}$ & MBS (ADAMS) & Car & $\mathrm{V}_{\mathrm{C}}$ \\
\hline (34) & k1y, d1y & MBS (A'GEM) & Car & $\mathrm{V}_{\mathrm{C}}$ \\
\hline (35) & $\mathrm{k} 1 \mathrm{x} / \mathrm{y}$ & - & - & $\mathrm{V}_{\mathrm{C}}$ \\
\hline (6) & $\mathrm{k} 1 \mathrm{~b} / \mathrm{s}$ & Own formulation & Bogie & $\mathrm{V}_{\mathrm{c}}$ \\
\hline (36) & $\mathrm{k} 1 \mathrm{x} / \mathrm{y}$ & Own formulation & 1/2 Car & $\mathrm{V}_{\mathrm{C}}$ \\
\hline (37) & $\mathrm{k} 1 \mathrm{x} / \mathrm{y} / \mathrm{s} / \mathrm{b}$ & Own formulation & Bogie & $\mathrm{V}_{\mathrm{c}}$ \\
\hline$(11)$ & $\mathrm{k} 1 \mathrm{x} / \mathrm{y}$ & - & - & $\mathrm{V}_{\mathrm{C}}$ \\
\hline (38) & $\mathrm{k} 1 \mathrm{x} / \mathrm{y}$ & Own formulation & Bogie & $\mathrm{V}_{\mathrm{C}}$ \\
\hline (39) & $\mathrm{k} 1 \mathrm{x} / \mathrm{y}$ & Own formulation & Bogie & $\mathrm{V}_{\mathrm{c}}$ \\
\hline$(40)$ & $\mathrm{k} 1 \mathrm{x} / \mathrm{y} / \mathrm{z}, \mathrm{d} 1 \mathrm{yz}, \mathrm{k} 2 \mathrm{x} / \mathrm{y} / \mathrm{z}, \mathrm{d} 2 \mathrm{x} / \mathrm{y} / \mathrm{z}$ & Own formulation & NA Train & vehicle stability \\
\hline$(41)$ & k1y & Own formulation & Wheelset & $\mathrm{V}_{\mathrm{c}}$ \\
\hline
\end{tabular}

Note (1: k: stiffness; d: damping; 1(2): primary (secondary) suspension; x: longitudinal; y: lateral; z: vertical; $\alpha$ : roll; $\gamma:$ yaw; b: bending; s: shear; w: wheel.

Note (2: FEM: 'Finite Element Method'; MBS: 'Multibody System'; Own formulation: the authors formulate the equations of motion. Note ( ${ }^{3}$ : A: articulated (with Jacobs bogies); NA: not articulated (with two bogies per carbody).

Note ${ }^{(4:} V_{C}$ : critical velocity.

TABLE 1 LITERATURE REVIEW: LINEAR STABILITY

\begin{tabular}{|c|c|c|c|c|}
\hline Reference & Modified parameter ${ }^{1}$ & $\begin{array}{l}\text { Method of } \\
\text { analysis }^{2}\end{array}$ & $\begin{array}{l}\text { Vehicle } \\
\text { model }^{3}\end{array}$ & Variables analyzed ${ }^{4}$ \\
\hline$(42)$ & $k 2 y / y$ & MBS (VAMPIRE) & Car & y wheelset \\
\hline$(43)$ & $k 1 y / y, d 1 y, k 2 y, d 2 x / y$ & Own formulation & Bogie & $\mathrm{V}_{\mathrm{C}}$ \\
\hline$(44)$ & $\mathrm{k} 1 \mathrm{x}, \mathrm{k} 1 \mathrm{y}$ & Own formulation & $1 / 2 \mathrm{Car}$ & $\mathrm{V}_{\mathrm{C}}$ \\
\hline$(45)$ & $k 2 x$ & Own formulation & 1/2 Car & $\mathrm{V}_{\mathrm{C}}$ \\
\hline$(46)$ & $\mathrm{k} 1 \mathrm{x} / \mathrm{y}$ & MBS (SIMPACK) & A Train & $\mathrm{V}_{\mathrm{C}}$ \\
\hline$(47)$ & k yaw damper & Own formulation & Car & ay bogie, ay carbody \\
\hline$(48)$ & $\mathrm{k} 1 \mathrm{y}, \mathrm{d} 1 \mathrm{y} / \mathrm{z}, \mathrm{d} 2 \mathrm{y} / \mathrm{y}$ & MBS (NUCARS) & Car & y wheelset \\
\hline (49) & $k 1 x / y, d 1 x / y, k 2 y$ & Own formulation & Car & y wheelset/bogie/carbody, $V_{C}$ \\
\hline$(50)$ & k1t & Own formulation & Car & $\mathrm{V}_{\mathrm{c}}$ \\
\hline$(51)$ & $\mathrm{k} 1 \mathrm{x} / \mathrm{y} / \mathrm{z}$ & Own formulation & Car & y wheelset, y bogie, y carbody \\
\hline$(52)$ & $\mathrm{k} 1 \mathrm{~b}$ & MBS (SIMPACK) & Car & $Y, V_{c}$ \\
\hline (53) & $\mathrm{k} 1 \mathrm{y} / \mathrm{y} / \mathrm{b} / \mathrm{s}, \mathrm{d} 1 \mathrm{y}, \mathrm{k} 2 \mathrm{y} / \mathrm{y}, \mathrm{d} 2 \mathrm{y} / \mathrm{Y}$ & Own formulation & Car & $\mathrm{V}_{\mathrm{c}}$ \\
\hline$(41)$ & k1y & Own formulation & Wheelset & y wheelset \\
\hline$(54)$ & $\mathrm{k} 1 \mathrm{y} / \mathrm{y}, \mathrm{d} 1 \mathrm{y} / \mathrm{y}, \mathrm{k} 2 \mathrm{x} / \mathrm{y}, \mathrm{d} 2 \mathrm{y}$ & Own formulation & Bogie & y wheelset, y bogie \\
\hline$(55)$ & $\mathrm{k} 1 \mathrm{x} / \mathrm{y}$ & Own formulation & Car & y wheelset, y bogie \\
\hline$(56)$ & $\mathrm{k} 1 \mathrm{x}, \mathrm{d} 1 \mathrm{y}$ & Own formulation & Car & y wheelset, $\Delta y$ wheelset \\
\hline (57) & $\mathrm{k} 1 \mathrm{x} / \mathrm{y} / \mathrm{z}, \mathrm{d} 1 \mathrm{x} / \mathrm{y}$ & Own formulation & Car & y wheelset, $\Delta y$ wheelset \\
\hline (58) & $\mathrm{k} 1 \mathrm{x}$ & - & - & $v_{C}$ \\
\hline$(59)$ & k, d yaw damper & MBS & - & $\mathrm{V}_{\mathrm{C}}$ \\
\hline
\end{tabular}

Note ${ }^{(1}: \mathrm{k}$ : stiffness; d: damping; $1(2)$ : primary (secondary) suspension; x: longitudinal; y: lateral; z: vertical; $\gamma$ : yaw; b: bending; s: shear; w: wheel; t: bump-stop.

Note (2: MBS: 'Multibody System'; Own formulation: the authors formulate the equations of motion.

Note ${ }^{3}$ : A: articulated (with Jacobs bogies); NA: not articulated (with two bogies per carbody).

Note ${ }^{(4}$ : $V_{C}$ : critical velocity; a: acceleration; Y: lateral wheel-rail force.

TABLE 2 LITERATURE REVIEW: NON-LINEAR STABILITY 


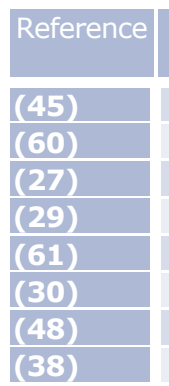

Modified parameter $^{1}$
k2z
k1x/y, $\Delta 1 z$
$k 1 b, d 1 x$
$k 1 x$
$k 1 x / y / z, k 2 y$
$k 1 x / y / z, d 1 x / y / z, k 2 y / z, d 2 y / z$
$k 1 b / s, \Delta 1 x / y$
$k 1 x / y$

\begin{tabular}{|c|c|}
\hline $\begin{array}{c}\text { Method of } \\
\text { analysis }^{2}\end{array}$ & $\begin{array}{c}\text { Vehicle } \\
\text { model }\end{array}$ \\
\hline Own formulation & Car \\
\hline MBS (GENSYS) & Car \\
\hline Own formulation & Bogie \\
\hline MBS (SIDIVE) & Car \\
\hline MBS (A'GEM) & Car \\
\hline MBS (A'GEM) & Car \\
\hline MBS (NUCARS) & Car \\
\hline Own formulation & Bogie \\
\hline
\end{tabular}

\begin{tabular}{|c|}
\hline Variables analyzed $^{3}$ \\
\hline Y/Q \\
\hline derailment risk \\
\hline $\mathrm{Y} / \mathrm{Q}$ \\
\hline $\mathrm{Y}, \mathrm{Y} / \mathrm{Q}$ \\
$\mathrm{Y} / \mathrm{Q}$ \\
$\mathrm{Y} / \mathrm{Q}$ \\
$\mathrm{Y} / \mathrm{Q}$ \\
$\mathrm{Y} / \mathrm{Q}$ \\
\hline
\end{tabular}

Note ${ }^{1}$ : k: stiffness; d: damping; f: friction; 1(2): primary (secondary) suspension; $x$ : longitudinal; y: lateral; z: vertical; $\gamma$ : yaw; b: bending; $\mathrm{s}$ s shear; $\Delta \mathrm{x}(\mathrm{z})$ : longitudinal (vertical) clearance.

Note (2: MBS: 'Multibody System'; Own formulation: the authors formulate the equations of motion.

Note ${ }^{3}: \mathrm{Y}(\mathrm{Q})$ : lateral (vertical) wheel-rail force.

TABLE 3 LITERATURE REVIEW: DERAILMENT RISK

\subsection{Track fatigue studies}

Table 4 gathers some bibliographic references on track fatigue.

\begin{tabular}{|c|c|c|c|c|}
\hline Reference & Modified parameter ${ }^{1}$ & $\begin{array}{l}\text { Method of } \\
\text { analysis }^{2}\end{array}$ & $\begin{array}{l}\text { Vehicle } \\
\text { model }^{3}\end{array}$ & Variables analyzed ${ }^{4}$ \\
\hline (22) & $k 1 x / y, d 1 x / y, k 2 x / y$ & Own formulation & Car & Y \\
\hline$(62)$ & $\mathrm{d} 1 \mathrm{z}$ & Own formulation & Bogie & Q \\
\hline$(28)$ & $\Delta 1 \mathrm{y}, \mathrm{k} 1 \mathrm{y}$ & Own formulation & Car & Y \\
\hline (34) & $\mathrm{k} 1 \mathrm{y}, \mathrm{d} 1 \mathrm{y}$ & MBS (A'GEM) & Car & Y \\
\hline (11) & $\mathrm{k} 1 \mathrm{~b}$ & - & - & Y \\
\hline (63) & $k 2 z, d 2 z$ & Own formulation & NA Train & z track \\
\hline
\end{tabular}

Note ${ }^{(1}$ : k: stiffness; d: damping; f: friction; 1(2): primary (secondary) suspension; $\mathrm{x}$ : longitudinal; $\mathrm{y}$ lateral; z: vertical; b: bending; s: shear; $\Delta \mathrm{y}$ : lateral clearance.

Note (2: MBS: 'Multibody System'; Own formulation: the authors formulate the equations of motion.

Note ${ }^{3}$ : A: articulated (with Jacobs bogies); NA: not articulated (with two bogies per carbody).

Note ${ }^{(4}: Y(Q)$ : lateral (vertical) wheel-rail force.

TABLE 4 LITERATURE REVIEW: TRACK FATIGUE

\subsection{RIDE QUALITY STUDIES}

Table 5 gathers some bibliographic references on ride quality.

\begin{tabular}{|c|c|c|c|c|}
\hline Reference & Modified parameter ${ }^{1}$ & $\begin{array}{l}\text { Method of } \\
\text { analysis }^{2}\end{array}$ & $\begin{array}{l}\text { Vehicle } \\
\text { model }^{3}\end{array}$ & Variables analyzed ${ }^{4}$ \\
\hline$(42)$ & $k 2 y$ & MBS (VAMPIRE) & Car & ay carbody, az carbody \\
\hline (23) & $\mathrm{k} 2 \mathrm{x} / \mathrm{y} / \mathrm{z} / \mathrm{a} / \mathrm{y}, \mathrm{d} 2 \mathrm{y} / \mathrm{z}$ & MBS (ADAMS) & Car & Wz \\
\hline$(64)$ & $k 2 y / y, d 2 y / y$ & Own formulation & A Train & ay carbody \\
\hline (65) & $\mathrm{k} 1 \mathrm{x} / \mathrm{y} / \mathrm{z}, \mathrm{d} 1 \mathrm{z}, \mathrm{k} 2 \mathrm{y} / \mathrm{z}, \mathrm{d} 2 \mathrm{y} / \mathrm{z} / \mathrm{a} / \mathrm{Y}$ & MBS (GENSYS) & Car & ay carbody \\
\hline$(66)$ & $k 1 z, d 1 z, k 2 z, d 2 z$ & Own formulation & Car & az carbody \\
\hline (67) & $\mathrm{k} 2 \mathrm{x} / \mathrm{y} / \mathrm{z}, \mathrm{d} 2$ & MBS (ADAMS) & Car & az carbody \\
\hline (30) & $\mathrm{k} 1 \mathrm{x} / \mathrm{y} / \mathrm{z}, \mathrm{d} 1 \mathrm{x} / \mathrm{y} / \mathrm{z}, \mathrm{k} 2 \mathrm{y} / \mathrm{z}, \mathrm{d} 2 \mathrm{y} / \mathrm{z}$ & MBS (A'GEM) & Car & comfort level \\
\hline$(20)$ & $\mathrm{k} 1 \mathrm{x}, \mathrm{k} 1 \mathrm{y}$ & MBS (GENSYS) & Car & ay carbody \\
\hline (68) & $k 2 z, d 2 z$ & Own formulation & Car & az carbody, comfort level \\
\hline (33) & $\mathrm{k} 2 \mathrm{y} / \mathrm{t}, \mathrm{d} 2 \mathrm{y} / \mathrm{z}, \Delta 2 \mathrm{y}$ & MBS (ADAMS) & Car & Wz \\
\hline$(69)$ & $\mathrm{k} 1 \mathrm{z}, \mathrm{k} 2 \mathrm{z}, \mathrm{d} 2 \mathrm{z}$ & Own formulation & 1/8 Car & $\mathrm{Q}$, az carbody, $\Delta \mathrm{z} 2$ \\
\hline$(70)$ & $k 2 y, d 2 y$ & Own formulation & Car & y carbody \\
\hline$(36)$ & $\mathrm{k} 1 \mathrm{z}, \mathrm{k} 2 \mathrm{z}$ & Own formulation & 1/8 Car & az carbody \\
\hline (63) & $k 2 z, d 2 z$ & Own formulation & NA Train & az carbody \\
\hline
\end{tabular}

Note $^{(1}$ : k: stiffness; d: damping; f: friction; $1(2)$ : primary (secondary) suspension; x: longitudinal; y: lateral; z: vertical; $\alpha$ : roll; $\gamma$ : yaw; $\Delta y$ : lateral clearance; t: bump-stop.

Note (2: MBS: 'Multibody System'; Own formulation: the authors formulate the equations of motion.

Note (3: A: articulated (with Jacobs bogies); NA: not articulated (with two bogies per carbody).

Note (4: Q: vertical wheel-rail force; a: acceleration; Wz: Sperling index; $\Delta z 2$ : deflection of the secondary suspension. 


\subsection{Compensation OF THE NOTED DEFICIENCIES}

As can be seen, the sensitivity to the elastic properties of the vehicle suspensions has been extensively treated before. However, all these references generally show very specific applications, focused on the study of a given vehicle, running over small track sections with simple geometry. They are also generally focused either on stability, on curve negotiation or on comfort studies, but seldom on the three types of study simultaneously. On the other hand, the range of values considered for the variability of each parameter is generally arbitrary, showing high variability from one study to another.

This study intends to extend the scope of the previous works, trying to cover as many parameters of interest as possible. For each parameter it is also intended to cover a range of values wide enough to consider many of the possible values that could be found in different railway vehicles.

Unlike the previous works, this study presents a more comprehensive approach, trying to simultaneously analyze the influence of all the different elastic properties of the vehicle in order to assess their impact on safety, track fatigue and ride quality, thus making it possible to determine which of these studies is more critical.

The same reference vehicle was employed to analyze the influence of all vehicle parameters considered in the above mentioned wider study: inertial properties, elastic properties and wheel-rail rolling properties. Three realistic track layouts were also used, with a cumulative length of $35 \mathrm{~km}$, covering a wide range of curve radii. In the same way, three different running speeds were considered for each track layout. Both the vehicle and track models are described in the next section.

In this way, it was intended to provide a wider view when analyzing the influence of the elastic properties of vehicle suspensions so as to assess their impact on vehicle dynamics.

\section{WORKING METHODOLOGY}

\subsection{SET-UP OF THE REFERENCE MODEL}

To perform the sensitivity analysis, multibody system (MBS) simulation techniques were employed. In particular, the SIMPACK commercial program was used. It allows simulating multi-body systems with especial features related with railway vehicle models, as the longitudinal guidance and the wheel-rail contact, which involves great forces transmitted through a small surface. SIMPACK has been tested in several benchmarks, as the Manchester benchmarks for railway vehicle dynamics (71), the ERRI Benchmark (72) or the Volpe LD benchmark (73).

The vehicle model represents a passenger car with two bogies, with the carbody resting on the elastic elements of the secondary suspension without any pivot or centre plate. The main bodies of the vehicle (carbody, bogie frames and wheelsets) were modeled as rigid bodies, connected to each other by means of linear springs and dampers that characterize the primary and secondary suspensions.

The vehicle model was parameterized with the aim of facilitating the variation of its features during the subsequent sensitivity analysis. Over 160 parameters were used. The vehicle model was built from smaller models of the individual components of the vehicle (carbody, bogie, primary suspension and secondary suspension). These sub-models are reusable and are assembled into the whole vehicle model. Numerical values were assigned to the different model parameters. These values were obtained from the median values of the data stored in the RVDynDB database, specifically made for this purpose (74), (7). 
Three track models were also built, following the indications stated in the standard EN14363. These models include curves with large $(R>600 \mathrm{~m})$, medium $(400 \mathrm{~m} \leq \mathrm{R} \leq 600 \mathrm{~m})$ and small $(250 \mathrm{~m} \leq \mathrm{R}<400 \mathrm{~m})$ radii, respectively called $R L$, $R M$ and $R S$. The specifications of this standard were also followed in the definition of track defects, specifically the alignment and longitudinal level, having chosen a track quality inside level QN1.

Vehicle and track models were coupled through the wheel-rail contact properties, defined by the Hertz theory for the normal forces, and by the Kalker's simplified theory for the tangential forces.

To consider the track elasticity in the model, track pieces were included under each wheelset. Each piece of track is directly supported by a pair of spring-damper elements.

The operating conditions were also set, following the specifications of the standard EN14363, taking into account that the maximum operating speed of the reference vehicle was $160 \mathrm{~km} / \mathrm{h}$. Table 6 gathers the speeds used in the models for each of the three track layouts.

\begin{tabular}{|cccc|}
\hline $\begin{array}{c}\text { Track } \\
\text { layout }\end{array}$ & $\mathrm{R}_{\min }[\mathrm{m}]$ & $\mathrm{R}_{\max }[\mathrm{m}]$ & $\mathrm{V}_{\max }[\mathrm{km} / \mathrm{h}]$ \\
\hline $\mathbf{R L}$ & 1620 & 1950 & 175 \\
\hline $\mathbf{R M}$ & 570 & 600 & 105 \\
\hline $\mathbf{R S}$ & 290 & 375 & 75 \\
\hline & TABLE 6 CURVE RADII AND RUNNING SPEEDS \\
\hline
\end{tabular}

\subsection{INITIAL CONDITIONS FOR THE SENSITIVITY ANALYSIS}

In order to determine the velocity ranges to be used in the sensitivity analysis, the dynamics of the reference vehicle were simulated at several speeds, starting with the lower speed and progressively increasing it until it was detected that at least one wheel completely left the track, this indicating a derailment by excessive speed. This way, the instability critical speed was identified for the track layout $R L$, as well as the minimum derailment speeds for each track model (Table 7).

For the RL track, the maximum speed, Vmax, was chosen just below the instability critical speed. The minimum speed, Vmin, was chosen so that the cant deficiency for the reference speed (Vref) would lie at the midpoint between the cant deficiencies for the extreme speeds Vmin and Vmax. The speed variation ranges for the track models RM and RS were defined so that they would have the same cant deficiency range as the first track model, RL. Table 7 shows the speed ranges so obtained for each track layout, together with their related cant deficiencies.

\begin{tabular}{|c|c|c|l|}
\hline $\begin{array}{c}\text { Track } \\
\text { layout }\end{array}$ & $\begin{array}{c}\text { Cant deficiency } \\
{[\mathrm{mm}]}\end{array}$ & $\begin{array}{c}\mathrm{V} \\
{[\mathrm{km} / \mathrm{h}]}\end{array}$ & \multicolumn{1}{|c|}{ Observations } \\
\hline \multirow{3}{*}{ RS } & 100 & 65 & Lower end \\
\hline \multirow{3}{*}{ RM } & 153 & 75 & Reference speed \\
\cline { 2 - 4 } & 201 & 83 & Upper end \\
\hline & 100 & 93 & Lower end \\
\hline \multirow{3}{*}{ RL } & 148 & 105 & Reference speed \\
\hline & 202 & 117 & Upper end \\
\hline & 99 & 160 & Lower end \\
\hline & 134 & 175 & Reference speed \\
\hline
\end{tabular}

A more detailed description of the process followed to determine the speed ranges to be applied in the sensitivity study can be found in (2). 


\subsection{DEFINITION OF SCENARIOS FOR THE SENSITIVITY ANALYSIS}

To perform the sensitivity analysis, the vehicle dynamics were simulated in different scenarios, which were built taking the vehicle reference model as starting point.

The first step in the definition of these scenarios was to modify independently, one at a time, the value of each of the parameters to be analyzed. Particularly, variations on the following parameters of the primary and the secondary suspensions were performed:

- Primary suspension: longitudinal, lateral and vertical stiffness (kx, ky, kz) and vertical damping (dz).

- Secondary suspension: lateral and vertical stiffness (ky, kz) and lateral and vertical damping (dy, dz).

Apart from the reference value, two additional values were considered for each parameter: a higher value and a lower value, corresponding to the percentiles 10 and 90 of the data set stored in the RVDynDB database (7), as indicated in Table 8. This table shows the values obtained for single suspension components.

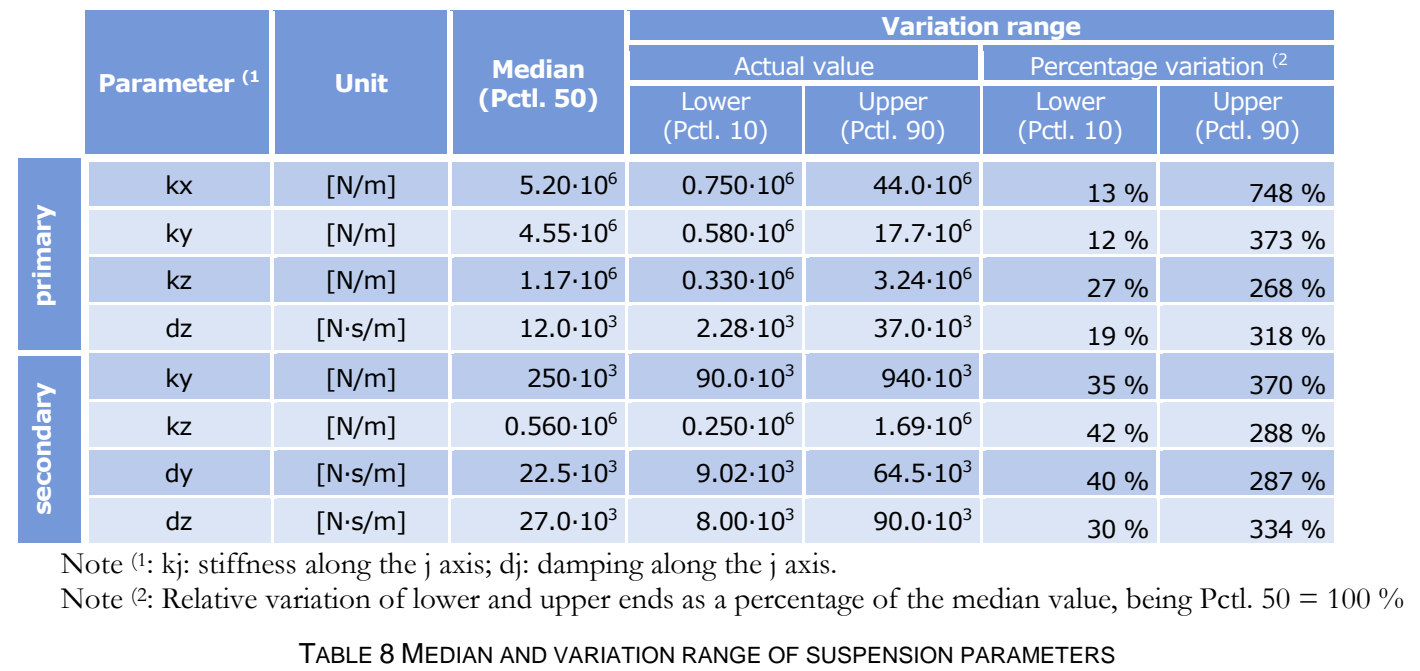

From Table 8, it can be observed that these parameters present both wide and skewed variation ranges. Although both the amplitude and asymmetry of the variation ranges were taken into account when assessing the influence of each parameter, they could affect the sensitivity study, probably making the results somewhat skewed towards parameters that naturally have a wide variation. However, it should be remembered that the present study intends to obtain qualitative, but not quantitative, results.

After modifying any vertical stiffness, a nominal force calculation was performed to recalculate the vertical reaction forces of the suspension springs, so that the vehicle could recover its initial equilibrium state, avoiding unrealistic vertical displacements of the carbody or even of the bogie.

Several operating conditions were considered for each of these values. Particularly, each vehicle model was combined with the track layouts $R S, R M$ and $R L$, all of them with track quality QN1. In turn, each track layout was run through at the running speeds Vmin, Vref and Vmax.

8 different scenarios were considered: 4 to analyze the influence of the elastic properties of the primary suspension and 4 to analyze the influence of the elastic properties of the secondary suspension. Once the models were ready, they were simulated, with a total of 
144 simulations ( 8 parameters $\cdot 2$ variations $\cdot 3$ speeds $\cdot 3$ track layouts), apart from the 3 simulations needed to analyze the reference case.

\subsection{POST-PROCESSING METHODOLOGY}

To make the comparison between the results of different simulations easier, the postprocessing methodology was systematized, reducing all the results of each simulation to a small set of indexes. To this end, the indications of the standard EN-14363 were followed. This standard proposes a statistical evaluation which allows the assessment of the vehicle dynamics from the safety, track fatigue and ride quality points of view.

As a whole, 5 assessment quantities were considered to evaluate running safety, 3 for track fatigue and another 5 for ride quality (Table 9).

\begin{tabular}{|c|c|c|c|}
\hline & Index & Assessment quantity & Symbol \\
\hline \multirow{5}{*}{ 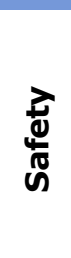 } & SAF-1 & Sum of wheelset guiding forces & $(\Sigma \mathrm{Y})_{2 \mathrm{~m}}$ \\
\hline & SAF-2 & Ratio of guiding force and wheel load & $(\mathrm{Y} / \mathrm{Q})$ \\
\hline & SAF-3 & Lateral acceleration of the bogie frame & $\ddot{y}_{s}^{+}$ \\
\hline & SAF-4 & Lateral acceleration of the carbody & $\ddot{y}_{s}^{*}$ \\
\hline & SAF-5 & Root mean square of the sum of wheelset guiding forces & $s \Sigma \mathrm{Y}$ \\
\hline \multirow{3}{*}{ 总 } & FAT-1 & Vertical wheel load & $Q$ \\
\hline & FAT-2 & Quasi-static lateral wheel force & $Y_{\text {qst }}$ \\
\hline & FAT-3 & Quasi-static vertical wheel force & $Q_{q s t}$ \\
\hline \multirow{5}{*}{ 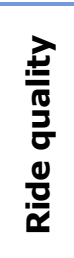 } & COM-1 & Lateral acceleration of the carbody & $\ddot{y}_{q}^{*}$ \\
\hline & COM-2 & Vertical acceleration of the carbody & $\ddot{z}_{q}^{*}$ \\
\hline & COM-3 & Root mean square of lateral acceleration of the carbody & s $\ddot{y}_{q}^{*}$ \\
\hline & COM-4 & Root mean square of vertical acceleration of the carbody & $\mathrm{s} \ddot{z}_{q}^{*}$ \\
\hline & COM-5 & Quasi-static lateral acceleration of the carbody & $\ddot{y}_{q s t}^{*}$ \\
\hline
\end{tabular}

The simulation results for each assessment quantity were post-processed following the indications of the standard EN-14363, in order to calculate their maximum estimated values.

The standard provides a limit value for each of the assessment quantities used to evaluate the vehicle dynamics, considering that the vehicle exhibits a suitable dynamic behaviour if the maximum estimated value for each assessment quantity is less than its related limit value.

\section{$4 \quad$ INDIVIDUAL RESULTS OF THE SENSITIVITY ANALYSIS}

After finishing the models and performing the appropriate simulations, the next step is to process the results obtained, following the indications of the standard EN-14363. The influence of a given parameter can then be determined by comparing each assessment index for all the simulations related to that parameter. These influences were independently evaluated for the different assessment quantities related to safety, track fatigue and ride quality studies. 


\subsection{DESCRIPTION OF THE TABLES USED}

To make comparisons easier, instead of using the safety (SAF), track fatigue (FAT) and ride quality $(\mathrm{COM})$ evaluation indexes directly obtained when processing the simulations results, a $\lambda$ ratio was computed for each index. This factor represents the ratio between a given index and its related limit value and it is expressed as a percentage, so that the values under $100 \%$ represent standard-compliant situations, while those over $100 \%$ represent non-compliant ones.

An influence indicator was then computed, combining the $\lambda$ ratios obtained for either the percentiles P10 or P90 and for the percentile P50 of the parameter being modified:

$$
I n f_{n}=\frac{\lambda_{n}-\lambda_{50}}{(P n-P 50) / P 50}, \quad n=10,90
$$

The influence indicator represents the ratio between the relative variation of the output and the relative variation of the modified parameter. Its denominator would be 1 if the modified parameter would increase a $100 \%$ from P50 to P90, or -1 if it would decrease a $100 \%$ from P50 to P10. Therefore, if the variation of the output is supposed to be linear, an influence indicator of $r \%$ means that the maximum estimated value of the assessment quantity being analyzed increases/decreases an $r \%$ of its related limit value when the modified parameter increases/decreases a $100 \%$. According to this interpretation, 5 different levels were set for the influence of a given parameter: low $(|\operatorname{lnf}|<10 \%)$; moderate $(10 \% \leq|\operatorname{lnf}|<25 \%)$; noticeable $(25 \% \leq|\operatorname{lnf}|<50 \%)$; high $(50 \% \leq|\operatorname{lnf}|<75 \%)$ and very high $(|\operatorname{lnf}| \geq 75 \%)$.

The highest influence was then computed from the influence indicators obtained for the results of simulations with similar scenarios (same evaluation index, track layout, type of track section and speed) that only differ in the value assigned to the parameter being analyzed:

$$
\widehat{\operatorname{Inf}}= \begin{cases}\operatorname{Inf} f_{10}, & \text { if }\left|\operatorname{Inf} f_{10}\right| \geq\left|\operatorname{Inf} f_{90}\right| \\ \operatorname{Inf} f_{90}, & \text { if }\left|\operatorname{Inf} f_{90}\right| \geq\left|\operatorname{Inf} f_{10}\right|\end{cases}
$$

The highest influences were grouped by type of track section (Cv, Tr, St) (seeTable 10). They were also grouped by track layout (RS, RM o RL) and by speed (Vmin, Vref and Vmax). Then, the global influence was calculated as the highest absolute value obtained inside each group.

The global influences were put together in a table (see Table 11), where columns 3-5 show the global influence found for each type of track section: curve, Cv, transition curve, Tr, and straight track, St; columns 6-8 show the global influence found for each track layout: $\mathrm{RS}$, RM and RL; and columns 9-11 show the global influence found for each speed category: Vmin, Vref and Vmax. The last column shows the highest global influence obtained in all these categories. This table allows to quickly determine which kind of dynamic behaviour leads to the most critical situations. The least critical results (below $10 \%$ ) were identified with an empty circle, $O$, the most critical (over $75 \%$ ) with a full black circle, and the intermediate ones with partially-filled circles: for influences between $10 \%$ and $25 \%$, for influences between $25 \%$ and $50 \%$, and 0 for influences between $50 \%$ and $75 \%$.

\subsubsection{Numerical example}

As an example, for the variations performed on the lateral stiffness of the secondary suspension, the stiffness takes the values: $P 10=0.09 \mathrm{kN} / \mathrm{mm} ; P 50=0.25 \mathrm{kN} / \mathrm{mm}$; $\mathrm{P} 90=0.94 \mathrm{kN} / \mathrm{mm}$. For the evaluation index SAF-1, the corresponding $\lambda$ ratios obtained for 
the simulations performed for RS track layout at Vmin in curved track sections, $\mathrm{Cv}$, are: $\lambda_{10}=30.1 \% ; \lambda_{50}=29.2 \% ; \lambda_{90}=29.1 \%$. From these values, the related influence indicators result in: $\operatorname{Inf}_{10}=0.9 \% /(-0.65)=-1.39 \%$ and $\operatorname{Inf}_{90}=-0.1 \% / 2.70=-0.04 \%$, the highest influence being $-1.39 \%$. This value is collected in the top-left cells of the three blocks of Table 10.

Table 10 shows the highest influences computed for the evaluation index SAF-1 when modifying the lateral stiffness of the secondary suspension. The left, central and right blocks respectively show the highest influences grouped by type of track section (Cv, Tr, St), by track layout (RS, RM, RL) and by speed (Vmin, Vref, Vmax). The value with highest absolute value of each column was highlighted in bold.

\begin{tabular}{|c|c|c|c|c|c|c|c|c|c|c|c|}
\hline & (Cv) & (Tr) & (St) & & RS & RM & RL & & Vmin & Vref & Vmax \\
\hline RS-Vmin & -1.39 & -2.63 & 2.07 & Cv-Vmin & -1.39 & 1.24 & 3.22 & RS-CV & -1.39 & -1.39 & -0.93 \\
\hline RS-Vref & -1.39 & -4.18 & 2.18 & Cv-Vref & -1.39 & 6.04 & 0.62 & RS-Tr & -2.63 & -4.18 & -2.94 \\
\hline RS-Vmax & -0.93 & -2.94 & 1.67 & Cv-Vmax & -0.93 & 10.38 & 15.02 & RS-St & 2.07 & 2.18 & 1.67 \\
\hline RM-Vmin & 1.24 & 0.31 & 2.04 & Tr-Vmin & -2.63 & 0.31 & -2.79 & $\mathrm{RM}-\mathrm{Cv}$ & 1.24 & 6.04 & 10.38 \\
\hline RM-Vref & 6.04 & 3.25 & 4.55 & Tr-Vref & -4.18 & 3.25 & -1.63 & RM-Tr & 0.31 & 3.25 & 8.52 \\
\hline RM-Vmax & 10.38 & 8.52 & 8.96 & Tr-Vmax & -2.94 & 8.52 & -4.49 & RM-St & 2.04 & 4.55 & 8.96 \\
\hline$R L-V \min$ & 3.22 & -2.79 & -4.65 & St-Vmin & 2.07 & 2.04 & -4.65 & RL-Cv & 3.22 & 0.62 & 15.02 \\
\hline RL-Vref & 0.62 & -1.63 & -5.89 & St-Vref & 2.18 & 4.55 & -5.89 & RL-Tr & -2.79 & -1.63 & -4.49 \\
\hline RL-Vmax & 15.02 & -4.49 & -15.95 & St-Vmax & 1.67 & 8.96 & -15.95 & RL-St & -4.65 & -5.89 & -15.95 \\
\hline
\end{tabular}

Finally, Table 11 shows the global influence for the variations in the lateral stiffness of the secondary suspension, $\mathrm{k} 2 \mathrm{Y}$, for the five safety criteria. Note that the values gathered in the second row are the highlighted values of Table 10 rounded to the nearest integer.

\begin{tabular}{|c|c|c|c|c|c|c|c|c|c|c|c|c|}
\hline \multirow{2}{*}{ Index } & \multirow{2}{*}{$\begin{array}{l}\text { Assess. } \\
\text { quantity }\end{array}$} & \multicolumn{4}{|c|}{ Type of track section } & \multicolumn{3}{|c|}{ Track layout } & \multicolumn{3}{|c|}{ Speed } & \multirow{2}{*}{ ИAX } \\
\hline & & & Cv & $\operatorname{Tr}$ & St & RS & RM & RL & Vmin & Vref & Vmax & \\
\hline$A F-1$ & $(\Sigma Y)_{2 m}$ & () & 150 & 96 & -160 & $-4 \odot$ & $10 \odot$ & -16 & -50 & 60 & $-16 \odot$ & -16 \\
\hline SAF-2 & $(Y / Q)_{2 m}$ & ) & $12 \odot$ & 17 & c & 170 & 40 & -13 & $11 C$ & 140 & $17 \odot$ & 17 \\
\hline SAF-3 & $\ddot{y}_{s}^{+}$ & () & 180 & -200 & -150 & 00 & -10 & -20 & -30 & -50 & $-20 \odot$ & -20 \\
\hline$A F-4$ & & C) & $20 \div$ & 130 & $17 €$ & 110 & $17 C$ & 20 & $20 c$ & $16 \odot$ & $17 \odot$ & 20 \\
\hline SAF-5 & $s \sum Y$ & () & $15 \odot$ & $-25 \odot$ & -110 & 00 & -10 & -25 & -30 & -20 & -250 & -25 \\
\hline
\end{tabular}

Variation range (P10; P90)trom $35 \%$ to $370 \%$ of the reference value (P50).
Legend:
Low (Influence $<10 \%$ );
Moderate $(10 \% \leq$ Influence $<25 \%)$
- Noticeable $(25 \% \leq$ Influence $<50 \%$
- High $(50 \% \leq$ Influence $<75 \%)$;
Very high (Influence $\geq 75 \%$ ).

TABLE 11 TABLE OF GLOBAL INFLUENCES: LATERAL STIFFNESS OF THE SECONDARY SUSPENSION

Whether the differences were classified by type of track section, by track layout or by speed, the maximum difference found is always the same (-25\% in this example). In this way, it is easy to identify which is the type of track section, the track layout or even the vehicle speed that show the largest influence. On the other hand, by looking at the values in the last column, it is also possible to identify which evaluation index provides the worst results.

In the following paragraphs, the global influence obtained when comparing the results of the different simulations performed is presented. Hereafter, for simplicity, global influences will be called just influences.

\subsection{INFLUENCE OF THE ELASTIC PROPERTIES OF THE PRIMARY SUSPENSION}

The following tables show the influence obtained when analyzing the following elastic properties of the primary suspension: 
- Longitudinal stiffness of the primary suspension, k1X (Table 12)

- Lateral stiffness of the primary suspension, k1Y (Table 13)

- Vertical stiffness of the primary suspension, k1Z (Table 14)

- Vertical damping of the primary suspension, $\mathrm{d} 1 \mathrm{Z}$

Those results related to $d 1 Z$ were omitted, as they present low influence in all the analyzed scenarios.

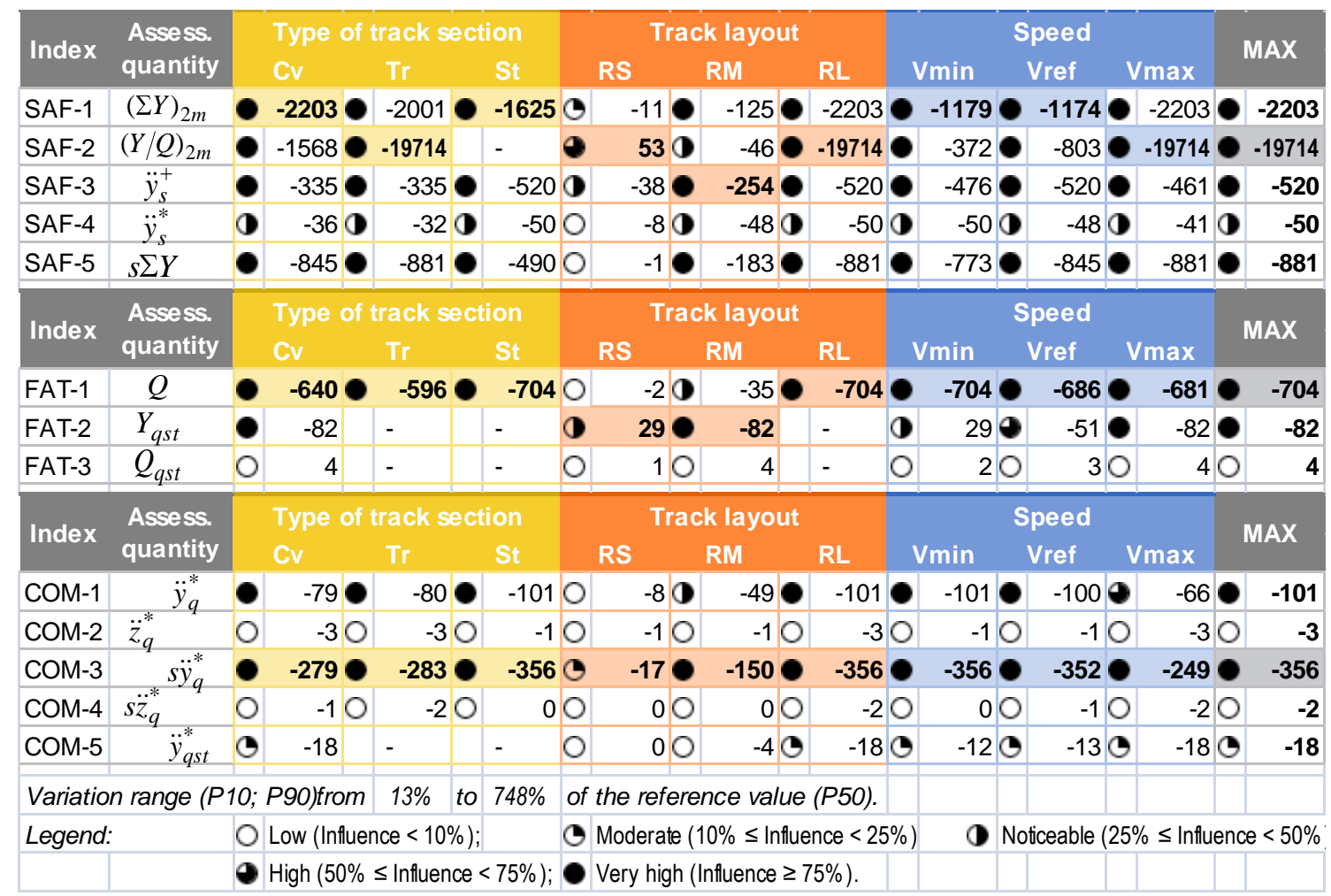

TABLE 12 GLOBAL INFLUENCE: LONGITUDINAL STIFFNESS OF THE PRIMARY SUSPENSION 


\begin{tabular}{|c|c|c|c|c|c|c|c|c|c|c|c|c|}
\hline \multirow{2}{*}{ Index } & \multirow{2}{*}{$\begin{array}{l}\text { Assess. } \\
\text { quantity }\end{array}$} & \multicolumn{4}{|c|}{ Type of track section } & \multicolumn{3}{|c|}{ Track layout } & \multicolumn{3}{|c|}{ Speed } & \multirow{2}{*}{ M } \\
\hline & & & Cv & $\operatorname{Tr}$ & St & RS & RM & $\mathbf{R L}$ & Vmin & Vref & $V \max$ & \\
\hline$A F-1$ & $(\Sigma Y)_{2 m}$ & 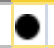 & $-185 \bullet$ & -5040 & -4120 & 70 & 80 & -504 & -830 & -85 & $-504 \bigcirc$ & -504 \\
\hline SAF-2 & $Q)_{2 m}$ & 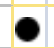 & -200 & -453 & 0 & 20 & -110 & -453 & -1110 & -103 & 453 & -453 \\
\hline SAF-3 & $\ddot{v}_{s}^{+}$ & - & $-294 \bigcirc$ & $-359 \bullet$ & -509 & -100 & $-53 \bigcirc$ & -5090 & -4910 & -5090 & -430 & -509 \\
\hline$A F-4$ & & () & -340 & -290 & -260 & -50 & -60 & -340 & -340 & $-23 c$ & -210 & -34 \\
\hline $\mathrm{F}-5$ & $Y$ & - & -880 & $-331 \bullet$ & -880 & 00 & $-4 \bullet$ & -3310 & -88 & -80 & -3310 & 331 \\
\hline \multirow{2}{*}{ Index } & \multirow{2}{*}{\multicolumn{2}{|c|}{$\begin{array}{l}\text { Assess. } \\
\text { quantity }\end{array}$}} & \multicolumn{3}{|c|}{ Type of track section } & \multicolumn{3}{|c|}{ Track layout } & \multicolumn{3}{|c|}{ Speed } & \multirow{2}{*}{ MAX } \\
\hline & & \multicolumn{2}{|r|}{$\mathrm{Cv}$} & $\operatorname{Tr}$ & St & RS & RM & RL & Vmin & Vref & $V \max$ & \\
\hline AT-1 & $Q$ & ( & $-34 \odot$ & $-55 \bigcirc$ & -920 & -20 & 30 & -920 & -500 & -440 & $-92 \bigcirc$ & -92 \\
\hline FAT-2 & ast & 0 & -7 & - & 0 & 10 & -7 & 0 & 10 & 20 & -70 & -7 \\
\hline AT-3 & $Q_{q s t}$ & 0 & 1 & - & 0 & -10 & 1 & - & 10 & 10 & 10 & \\
\hline \multirow{2}{*}{ Index } & \multirow{2}{*}{\multicolumn{2}{|c|}{$\begin{array}{l}\text { Assess. } \\
\text { quantity }\end{array}$}} & \multicolumn{3}{|c|}{ Type of track section } & \multicolumn{3}{|c|}{ Track layout } & \multicolumn{3}{|c|}{ Speed } & \\
\hline & & & $\mathrm{Cv}$ & $\operatorname{Tr}$ & St & RS & RM & $\mathbf{R L}$ & Vmin & Vref & $V \max$ & \\
\hline COM-1 & $\ddot{y}_{q}^{*}$ & () & -420 & -400 & -460 & -40 & -50 & -460 & -420 & -460 & -250 & -46 \\
\hline COM-2 & & 0 & -10 & 00 & 00 & 00 & 00 & -10 & 00 & -10 & 00 & -1 \\
\hline COM-3 & $s \ddot{y}_{a}^{*}$ & 0 & $-136 \bigcirc$ & $-126 \bigcirc$ & -1470 & -90 & -120 & -1470 & $-136 \bigcirc$ & -1470 & -890 & -147 \\
\hline COM-4 & $q$ & 0 & 00 & 00 & 00 & 00 & 00 & 00 & 00 & 00 & 00 & \\
\hline COM-5 & $\ddot{y}_{q s t}^{*}$ & 0 & 3 & - & 0 & 00 & 00 & 30 & 10 & 20 & 30 & \\
\hline Variation & nge & $10 ;$ & P90)from & $12 \%$ to & $373 \%$ of & the referen & nce value & (P50). & & & & \\
\hline Legend: & & 0 & Low (Influen & רce $<10 \%$ ); & () & Moderate (10 & $10 \% \leq$ Influer & ence $<25 \%$ ) & (1) No & loticeable (25 & ffluence & $e<50 \%$ \\
\hline & & - & High $(50 \%$ & $\leq$ Influence $<$ & $<75 \%) ;$ & Very high (In & Influence $\geq 7$ & $75 \%)$ & & & & \\
\hline & & & TABL & $\mathrm{L}$ & L I & CE: LATE & ES & SS OF & & . & & \\
\hline ay & s. & & Type of $t$ & track secti & tion & Track & yout & & & Speed & & \\
\hline$e x$ & quantity & & Cv & Tr & St & RS & & 101 & Vmin & Vref & $x$ & \\
\hline SAF-1 & $(\Sigma Y)_{2 m}$ & 0 & 60 & 30 & -20 & -20 & 30 & 60 & -20 & -20 & 60 & \\
\hline SAF-2 & $(Q)_{2 m}$ & 0 & $4 C$ & 5 & 0 & 50 & 20 & 20 & 40 & 40 & 50 & \\
\hline SAF-3 & & 0 & 70 & -20 & 10 & 00 & 00 & 70 & 10 & 20 & 70 & 7 \\
\hline$=-4$ & & 0 & -3 & -3 & 40 & 4 & -30 & -30 & 40 & -30 & -30 & \\
\hline-5 & $Y$ & 0 & 80 & -10 & -30 & 00 & 00 & 80 & 00 & -10 & 80 & 8 \\
\hline lex & . & & Type c & track s & tion & rack & yout & & & Speed & & \\
\hline & quar & & Cv & Tr & St & RS & $\mathbf{R}$ & $\mathbf{R L}$ & in & Vref & $\mathrm{Vn}$ & \\
\hline FAT-1 & $Q$ & 0 & -80 & -70 & 40 & -50 & -70 & -80 & -40 & -60 & -80 & -8 \\
\hline FAT-2 & $Y_{q s t}$ & 0 & 1 & - & 0 & 10 & 1 & 0 & 00 & 10 & 10 & 1 \\
\hline FAT-3 & qst & 0 & -4 & - & 0 & -40 & -4 & 0 & -20 & -30 & -40 & -4 \\
\hline & & & Type & tra & tion & $T$ & ut & & & Speed & & \\
\hline & & & Cv & $\operatorname{Tr}$ & St & RS & RM & RL & $\min$ & Vref & $V \max$ & \\
\hline COM-1 & $\ddot{y}_{q}^{*}$ & 0 & 30 & -30 & 30 & 30 & -30 & 10 & 30 & -20 & 20 & 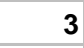 \\
\hline COM-2 & & () & 210 & 220 & 250 & -60 & 250 & 100 & 100 & 180 & 250 & 25 \\
\hline COM-3 & $s \ddot{y}_{c}$ & 0 & 100 & -90 & 100 & 100 & -90 & 10 & 100 & 80 & 70 & 10 \\
\hline COM-4 & $\ddot{z}_{q}^{*}$ & 1 & 420 & 390 & 480 & -120 & 480 & 190 & 190 & 310 & 480 & 48 \\
\hline COM-5 & $\ddot{y}_{q s}^{*}$ & 0 & 0 & - & 0 & 00 & 00 & 00 & 00 & 00 & 00 & 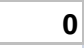 \\
\hline
\end{tabular}

Variation range (P10; P90)from $27 \%$ to $268 \%$ of the reference value (P50).

\begin{tabular}{|l|l|l|l|}
\hline Legend: & Low (Influence $<10 \%)$; & Moderate $(10 \% \leq$ Influence $<25 \%)$ & Noticeable $(25 \% \leq$ Influence $<50 \%$ \\
& & High $(50 \% \leq$ Influence $<75 \%) ;$ & Very high (Influence $\geq 75 \%)$.
\end{tabular}

TABLE 14 GLOBAL INFLUENCE: VERTICAL STIFFNESS OF THE PRIMARY SUSPENSION

From these results, it can be concluded that:

- $\mathrm{k} 1 \mathrm{X}$ shows a very high influence for any study (safety, track fatigue and ride quality). 
- k1Y shows a very high influence for any study. However, it shows low influence for track fatigue studies with RS or RM track layouts at any speed, as well as for ride quality studies with RS track layout at any speed.

- $\quad k 1 Z$ shows low influence for safety and track fatigue studies and noticeable influence for ride quality studies.

- $\quad$ d1Z shows low influence for any study.

\subsection{INFLUENCE OF THE ELASTIC PROPERTIES OF THE SECONDARY SUSPENSION}

The following tables show the influence obtained when analyzing the following elastic properties of the secondary suspension:

- Lateral stiffness of the secondary suspension, k2Y (Table 15)

- Vertical stiffness of the secondary suspension, k2Z (Table 16)

- Lateral damping of the secondary suspension, d2Y (Table 17)

- Vertical damping of the secondary suspension, d2Z (Table 18)

\begin{tabular}{|c|c|c|c|c|c|c|c|c|c|c|c|c|}
\hline \multirow{2}{*}{ Index } & \multirow{2}{*}{$\begin{array}{l}\text { Assess. } \\
\text { quantity }\end{array}$} & \multicolumn{4}{|c|}{ Type of track section } & \multicolumn{3}{|c|}{ Track layout } & \multicolumn{3}{|c|}{ Speed } & \multirow{2}{*}{ MAX } \\
\hline & & \multicolumn{2}{|r|}{ Cv } & $=$ & St & RS & RM & $\mathbf{R L}$ & Vmin & Vref & $V \max$ & \\
\hline SAF-1 & $(\Sigma Y)_{2 m}$ & - & 150 & 90 & $-16 C$ & -40 & 100 & -160 & -50 & 60 & -160 & -16 \\
\hline SAF-2 & $(Y / Q)_{2 m}$ & - & $12 \odot$ & 17 & - & 170 & 40 & $-13 \odot$ & $11 c$ & 140 & $17 \odot$ & 17 \\
\hline SAF-3 & $\ddot{y}_{s}^{+}$ & () & $18 \odot$ & $-20 \bullet$ & $-15 C$ & 00 & $-1 \odot$ & -200 & -30 & -50 & $-20 \odot$ & -20 \\
\hline SAF-4 & j & () & $20 \odot$ & 130 & $17 C$ & 110 & $17 \odot$ & 20 & $20 c$ & $16 \odot$ & $17 \odot$ & 20 \\
\hline$A F-5$ & $Y$ & - & $15 \odot$ & -250 & $-11 C$ & 00 & -10 & -250 & -30 & -20 & -250 & -25 \\
\hline \multirow{2}{*}{ Index } & \multirow{2}{*}{\multicolumn{2}{|c|}{$\begin{array}{l}\text { Assess. } \\
\text { quantity }\end{array}$}} & \multicolumn{3}{|c|}{ Type of track section } & \multicolumn{3}{|c|}{ Track layout } & \multicolumn{3}{|c|}{ Speed } & \multirow{2}{*}{ MAX } \\
\hline & & & $\mathrm{Cv}$ & $\operatorname{Tr}$ & St & RS & RM & RL & Vmin & Vref & Vmax & \\
\hline FAT-1 & $Q$ & 1 & $-28 \odot$ & -190 & -50 & -280 & -250 & -260 & $-14 C$ & -220 & $\quad-280$ & -28 \\
\hline FAT-2 & $Y_{q s t}$ & 0 & 5 & - & - & 50 & 2 & - & 40 & 40 & 50 & 5 \\
\hline FAT-3 & $Q_{q s t}$ & () & -13 & - & - & -130 & -11 & - & $-7 C$ & -10 & -130 & -13 \\
\hline dex & Asses & & Type o & track sect & tion & Track & yout & & & Speed & & \\
\hline 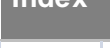 & quantity & & Cv & Tr & St & RS & RM & RL & Vmin & Vref & $V \max$ & \\
\hline COM-1 & $\ddot{v}^{*}$ & () & 20 & 200 & $17 C$ & 100 & 160 & 200 & $20 c$ & 170 & 16 & 20 \\
\hline COM-2 & $\ddot{z}_{q}^{*}$ & 0 & -10 & 00 & 00 & -10 & 00 & 00 & -10 & 00 & 00 & -1 \\
\hline COM-3 & $s \ddot{y}_{q}^{*}$ & $\bullet$ & 540 & 490 & 450 & 260 & 420 & $54 \%$ & 540 & 450 & 420 & 54 \\
\hline COM-4 & $q$ & 0 & 20 & 20 & 00 & -10 & 20 & 00 & -10 & 20 & 20 & 2 \\
\hline COM-5 & $\ddot{y}_{q s t}^{*}$ & 0 & 0 & - & - & 00 & 00 & 00 & 00 & 00 & 00 & 0 \\
\hline Variation & $n$ range & & P90)from & $35 \%$ to & $370 \% \quad 0$ & of the referen & nce value & (P50). & & & & \\
\hline Legend: & & O & Low (Influen & nce < 10\%); & & () Moderate (10 & $10 \% \leq$ Influer & ence $<25 \%$ & (1) $\mathrm{N}$ & eable $\left(25^{\circ}\right.$ & $\leq \ln \| \mathrm{C}$ & $50 \%$ \\
\hline & & $\boldsymbol{\bullet}$ & High $(50 \%$ & $\leq$ Influence & $<75 \%) ;$ & Very high (In & Influence $\geq 7$ & 75\%). & & & & \\
\hline
\end{tabular}

TABLE 15 GLOBAL INFLUENCE: LATERAL STIFFNESS OF THE SECONDARY SUSPENSION 


\begin{tabular}{|c|c|c|c|c|c|c|c|c|c|c|c|c|}
\hline \multirow{2}{*}{ Index } & \multirow{2}{*}{$\begin{array}{l}\text { Assess. } \\
\text { quantity }\end{array}$} & \multicolumn{4}{|c|}{ Type of track section } & \multicolumn{3}{|c|}{ Track layout } & \multicolumn{3}{|c|}{ Speed } & \multirow{2}{*}{ IAX } \\
\hline & & & Cv & \multirow{2}{*}{${ }^{\operatorname{Tr}} 90$} & St & RS & RM & RL & Vmin & Vref & Vmax & \\
\hline AF-1 & $(\Sigma Y)_{2 m}$ & () & 170 & & -30 & -50 & 100 & $17 C$ & -30 & $6 c$ & $17 \mathrm{C}$ & 1 \\
\hline $\mathrm{F}-2$ & $Q)_{2 m}$ & c & 120 & 15 & c & 150 & 60 & 30 & 90 & $12 \mathrm{C}$ & $15 c$ & 1 \\
\hline F-3 & & 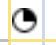 & 70 & 40 & -10 & 00 & -10 & $17 \mathrm{C}$ & 10 & $3 c$ & $7 \mathrm{C}$ & 1 \\
\hline $\mathrm{F}-4$ & & 0 & -50 & -40 & 60 & 60 & -50 & $-4 C$ & 60 & -50 & $-4 C$ & \\
\hline $\mathrm{F}-5$ & $Y$ & 0 & 180 & -10 & 10 & 00 & 00 & $18 C$ & 00 & $-1 c$ & $18 \mathrm{C}$ & 1 \\
\hline \multirow{2}{*}{ Index } & \multirow{2}{*}{\multicolumn{2}{|c|}{$\begin{array}{l}\text { Assess. } \\
\text { quantity }\end{array}$}} & \multicolumn{3}{|c|}{ Type of track section } & \multicolumn{3}{|c|}{ Track layout } & & $\Delta x$ \\
\hline & & & Cv & $\operatorname{Tr}$ & St & RS & RM & RL & Vmin & Vref & Vmax & $\ln x$ \\
\hline AT-1 & $Q$ & 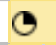 & -250 & -160 & $-4 C$ & -25 & -210 & $-21 c$ & -110 & $-18 C$ & $-25 c$ & -2 \\
\hline АТ-2 & $Y_{q s t}$ & 0 & 3 & - & & 30 & -1 & & 20 & 30 & 30 & \\
\hline $\mathrm{T}-3$ & $q s t$ & () & -11 & - & - & -110 & -9 & 0 & -60 & $-8 c$ & $-11 C$ & 1 \\
\hline & & & Type c & track se & tion & Trac & ck layout & & & Speed & & iny \\
\hline$d e x$ & & & Cv & $\operatorname{Tr}$ & St & RS & IM & RL & Vmin & ret & Vmax & $A \bar{A}$ \\
\hline DM-1 & $\ddot{y}_{q}^{*}$ & 0 & 50 & 40 & 60 & 60 & -50 & 30 & 60 & 50 & $-5 C$ & \\
\hline DM-2 & & () & 320 & 34 ( & $40 c$ & 15 Ф & $40 \oplus$ & $31 \boldsymbol{\sigma}$ & $30 \oplus$ & 36 & $40 a$ & 4 \\
\hline M-3 & $s \ddot{y}_{q}^{*}$ & () & 130 & $-14 \odot$ & $-16 c$ & 140 & -160 & $3 c$ & $-16 C$ & $-12 C$ & $11 \mathrm{C}$ & -1 \\
\hline M-4 & 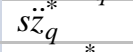 & $\bullet$ & 650 & $63 \circ$ & $77 C$ & $25 \bullet$ & 770 & 630 & $59 \bullet$ & 68 & 77 & 7 \\
\hline COM-5 & $\ddot{y}_{q s t}^{*}$ & 0 & 1 & 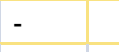 & O & 00 & 00 & 10 & 00 & 00 & 10 & \\
\hline Variatio & in range & $10 ; \mathrm{F}$ & 990)from & $42 \%$ to & $288 \%$ & of the refere & ence value & $e(P 50)$. & & & & \\
\hline egend. & & OL & .ow (Influen & nce < $10 \%)$; & & 5 Moderate ( & $10 \% \leq \operatorname{lnflu}$ & ence $<25 \%$ & () No & Noticeable (25 & $25 \% \leq$ Influer & $n c e<50^{\circ}$ \\
\hline & & - । & -igh $(50 \%$ & $\leq$ Influence & $<75 \%)$ & - Very high ( & (Influence $\geq$ & $75 \%)$. & & & & \\
\hline & & & TABLE 16 & GLOBAL I & INFLUENCE & E: VERTICAL & STIFFNES & s of & ARY & ISPENSI & SION & \\
\hline doy & & & Type of 1 & track sec & tion & Trac & ck layout & & & Speed & & $\mathrm{y}$ \\
\hline wex & ntity & & Cv & $\operatorname{Tr}$ & St & RS & M & RL & Vmin & Vref & Vmax & IAn \\
\hline AF-1 & $(\Sigma Y)_{2 m}$ & () & -36 & $-168 \bullet$ & $-180 \mathrm{C}$ & 20 & 8 & -1800 & 60 & 8 & -180 & -18 \\
\hline AF-2 & $Q)_{2 m}$ & () & $-44 \bullet$ & -154 & - & 10 & $1 \bullet$ & $-154 \mathrm{O}$ & 10 & $-2 \bullet$ & -154 & -15 \\
\hline AF-3 & $\ddot{y}_{s}^{+}$ & $\bullet$ & $-52 \bullet$ & $-296 \bullet$ & $-283 C$ & 00 & $1 \bullet$ & $-296 \mathrm{C}$ & 10 & $-5 \bullet$ & -296 & -29 \\
\hline-4 & $\ddot{y}_{s}^{*}$ & 0 & $10 \bullet$ & $-11 \odot$ & $-12 c$ & -120 & -110 & $10 \mathrm{c}$ & -110 & $-12 \odot$ & $-12 c$ & -1 \\
\hline AF-5 & $s \Sigma Y$ & - & $-76 \bullet$ & $-350 \bullet$ & -2350 & 00 & $-1 \bullet$ & $-350 \mathrm{C}$ & -40 & $-10 \bullet$ & -350 & -35 \\
\hline dex & Asses & & Type of & track sec & tion & Trac & yout & & & Speed & & $X$ \\
\hline$C_{n}$ & qu & & Cv & $\operatorname{Tr}$ & St & RS & M & RL & Vmin & Vref & Vmax & $\ln$ \\
\hline T-1 & $Q$ & 0 & -30 & $-10 \oplus$ & -310 & 00 & -10 & -310 & -10 & -10 & -310 & -3 \\
\hline & st & 0 & -2 & - & - & 00 & -2 & 0 & -20 & -20 & $-2 C$ & - \\
\hline T-3 & $Q_{q s t}$ & 0 & 0 & - & - & 00 & 0 & O & 00 & 00 & 00 & \\
\hline dex & $\sec$ & & Type o & track sec & tion & Trac & yout & & & Speed & & \\
\hline & & & Cr & $\operatorname{Tr}$ & St & RS & RM & RL & Vmin & Vref & Vmax & An \\
\hline$M-1$ & $\ddot{y}_{q}^{*}$ & $\odot$ & $-12 \bullet$ & $13 \bullet$ & $-13 c$ & -130 & $-10 \bullet$ & $13 \mathrm{c}$ & 110 & 130 & $13 c$ & 1. \\
\hline-2 & & 0 & 20 & 00 & 00 & 00 & 00 & 20 & 00 & 00 & 20 & ) \\
\hline-3 & $s \ddot{y}_{q}^{*}$ & (1) & -320 & $-31 \oplus$ & -340 & -340 & -27 & 280 & -270 & -340 & $-32 d$ & -3 \\
\hline COM-4 & $q$ & 0 & 00 & 00 & 00 & 00 & 00 & 00 & 00 & 00 & 00 & r \\
\hline COM-5 & $\ddot{y}_{q s t}^{*}$ & 0 & 1 & - & 0 & 00 & 00 & 10 & 00 & 00 & 10 & ) \\
\hline Variatio & $n$ range $(P$ & $10 ;$ & 990)from & $40 \%$ to & $287 \%$ & of the refere & ence value & (P50). & & & & \\
\hline Legend: & & 0 & Low (Influer & $n c e<10 \%)$; & & 3 Moderate ( & $10 \% \leq \operatorname{lnflu}$ & ence $<25 \%$ & () No & Noticeable (25 & $25 \% \leq$ Influer & $n c e<50^{\circ}$ \\
\hline & & & $\operatorname{ligh}(50$ & $\leq$ Influence & $<75 \%)$ & Very high ( & (Influence $\geq$ & 75 & & & & \\
\hline
\end{tabular}

TABLE 17 GLOBAL INFLUENCE: LATERAL DAMPING OF THE SECONDARY SUSPENSION 


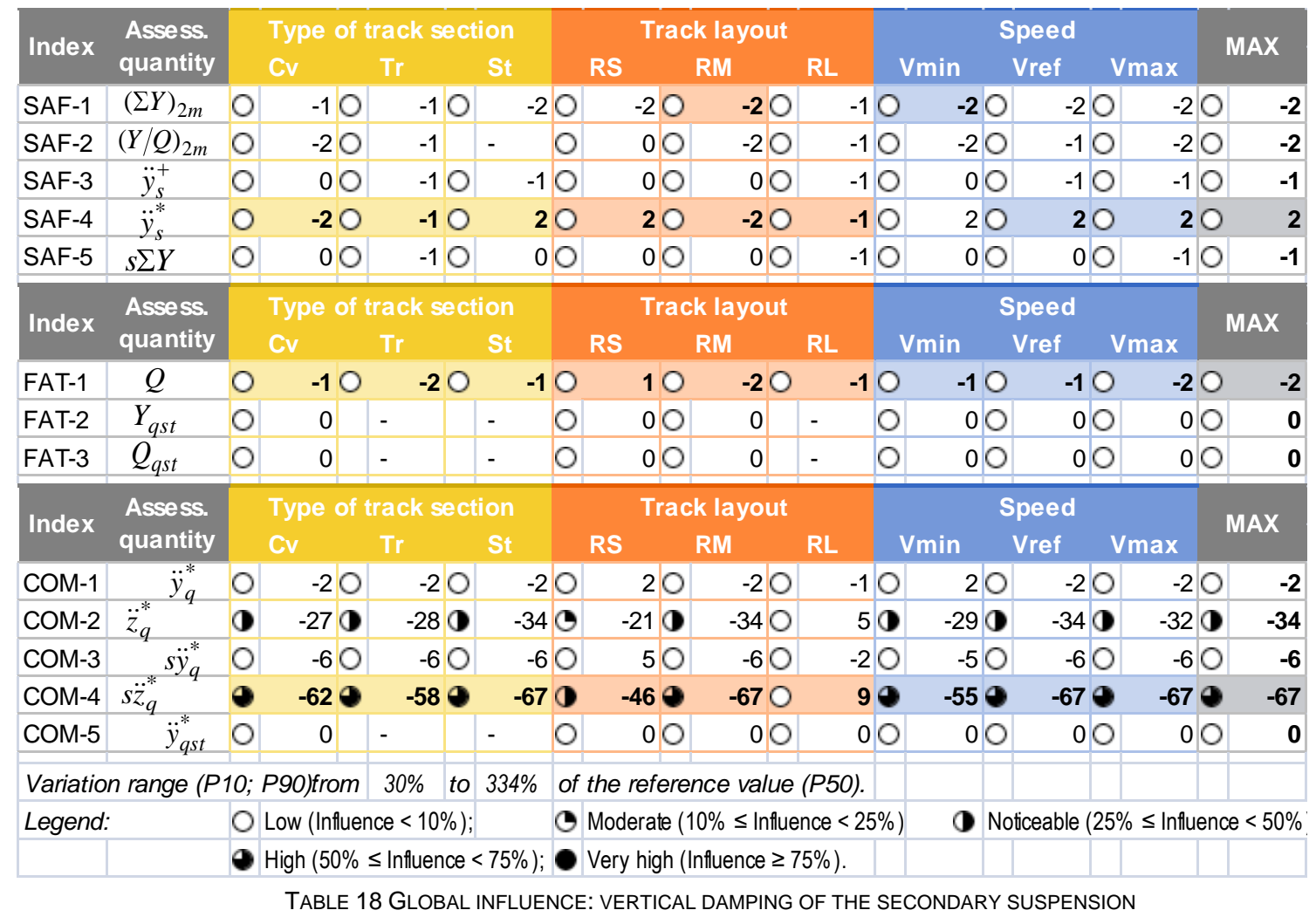

From these results it can be concluded that:

- k2Y shows moderate influence for safety studies, noticeable influence for track fatigue studies and high influence for ride quality studies.

- $\quad$ k2Z shows moderate influence for safety and track fatigue studies and very high influence for ride quality studies. However, it shows low influence for safety studies with RM track layouts at any speed, as well as at Vmin with any track layout.

- d2Y shows noticeable influence for ride quality studies and very high influence for safety studies. For track fatigue studies, it also shows noticeable influence for $R L$ track layouts at Vmax, showing low influence in any other condition.

- $\quad$ d2Z shows low influence for safety and track fatigue studies, and high influence for ride quality studies. However, it can show a low influence for ride quality studies with $\mathrm{RL}$ track layouts at any speed.

\subsection{FURTHER COMMENTS}

Influences of hundreds and even thousands of percent respect the related limit values were obtained for $\mathrm{k} 1 \mathrm{X}, \mathrm{k} 1 \mathrm{Y}$ and $\mathrm{d} 2 \mathrm{Y}$. For all these parameters, the safety index SAF-5 was also over $100 \%$ for $\mathrm{RL}$ track layouts at Vmax, thus indicating that the vehicle become unstable under such conditions, so conditioning the high influences found. However, lower influences may be found for these parameters if they had not been varied independently from the other elastic properties, or even if they had been varied in lower steps.

\section{COMPARISON OF RESULTS OF THE SENSITIVITY ANALYSIS}

In this paragraph, the results obtained in the sensitivity analysis are compared. The conclusions obtained from this analysis are also presented here. To have a more 
comprehensive view, results are grouped into two different categories: elastic properties of the primary suspension and elastic properties of the secondary suspension.

Within each group, the results are gathered in the same table, showing the characteristics of the most critical scenarios found when analyzing the influence of each parameter. The notations used for the output quantities shown in these tables were explained in Table 9.

\subsection{INFLUENCE OF THE ELASTIC PROPERTIES OF THE PRIMARY SUSPENSION}

Table 19 summarizes the characteristics of the most critical scenarios found when analyzing the influence of the elastic properties of the primary suspension.

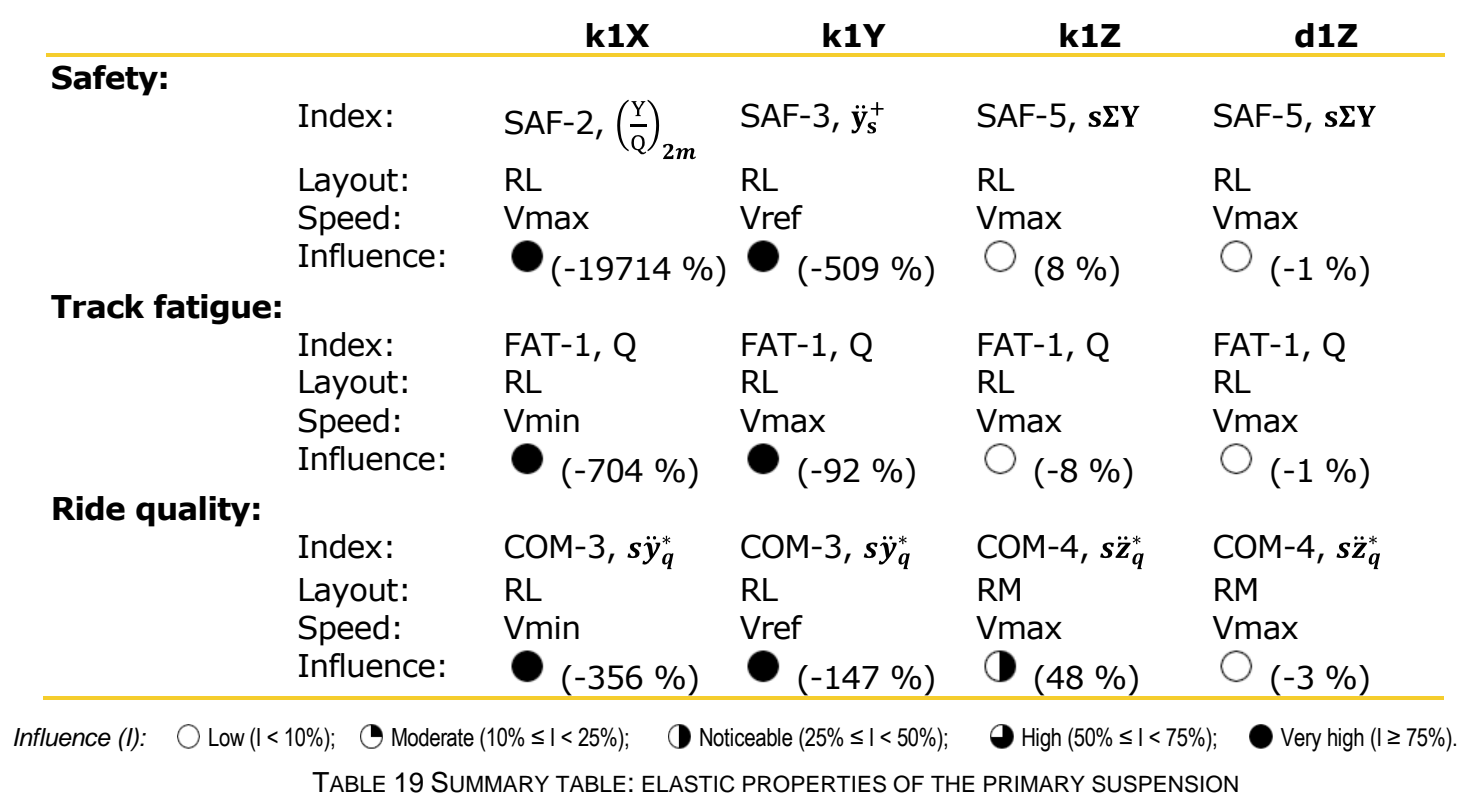

In view of these results, the parameter to which vehicle dynamic behaviour is most sensitive is $\mathrm{k} 1 \mathrm{X}$, followed by $\mathrm{k} 1 \mathrm{Y}$, both showing very high Influence for safety, track fatigue and ride quality studies, the highest influences being found when running on the $R L$ track layout; they are followed by $\mathrm{k} 1 \mathrm{Z}$, showing noticeable influence for ride quality studies and low influence for safety and track fatigue studies, the highest influences being found when running at Vmax. The only parameter that shows low influence for safety, track fatigue and ride quality studies is $\mathrm{d} 1 \mathrm{Z}$.

\subsection{INFLUENCE OF THE ELASTIC PROPERTIES OF THE SECONDARY SUSPENSION}

Table 20 summarizes the characteristics of the most critical scenarios found when analyzing the influence of the elastic properties of the secondary suspension. 


\begin{tabular}{|c|c|c|c|c|c|}
\hline & & k2Y & k2Z & d2Y & d2z \\
\hline \multicolumn{6}{|l|}{ Safety: } \\
\hline & Index: & SAF-5, $\mathbf{s} \boldsymbol{\Sigma} \mathbf{Y}$ & SAF-5, $\mathbf{s} \boldsymbol{\Sigma} \mathbf{Y}$ & SAF-5, $\mathbf{s} \boldsymbol{\Sigma} \mathbf{Y}$ & SAF-4, $\ddot{y}_{s}^{*}$ \\
\hline & Layout: & $\mathrm{RL}$ & & & \\
\hline & Speed: & Vmax & Vmax & Vmax & Vmax \\
\hline & Influence: & $(-25 \%)$ & (18 \%) & $(-350 \%)$ & (2\%) \\
\hline \multicolumn{6}{|c|}{ Track fatigue: } \\
\hline & Index: & FAT- $1, Q$ & FAT- $1, Q$ & FAT- $1, Q$ & FAT- $1, Q$ \\
\hline & Layout: & RS & & & \\
\hline & Speed: & Vmax & Vmax & Vmax & Vmax \\
\hline & Influence: & (-28 \%) & $(-25 \%)$ & $(-31 \%)$ & $(-2 \%)$ \\
\hline \multicolumn{6}{|c|}{ Ride quality: } \\
\hline & Index: & $\mathrm{COM}-3, s \ddot{y}_{q}^{*}$ & $\mathrm{COM}-4, s \ddot{z}_{q}^{*}$ & $\mathrm{COM}-3, s \ddot{y}_{q}^{*}$ & $\mathrm{COM}-4, s \ddot{z}_{q}^{*}$ \\
\hline & Layout: & & $\mathrm{RM}$ & RS & $\mathrm{RM}$ \\
\hline & Speed: & Vmin & Vmax & Vref & Vref \\
\hline & Influence: & (54 \%) & (77\%) & (-34\%) & (-67\%) \\
\hline
\end{tabular}

In view of these results, the parameters to which vehicle dynamic behaviour is most sensitive are $d 2 Y$ and k2Z. The former shows very high influence for safety studies and noticeable influence for both track fatigue and ride quality studies; the second one shows very high influence for ride quality studies and moderate influence for both safety and track fatigue studies, the highest influences being found when running at Vmax. They are followed by k2Y, with high influence for ride quality studies, noticeable influence for track fatigue studies and moderate influence for safety studies. The least sensitive parameter is d2Z, showing high influence for ride quality studies and low influence for both safety and track fatigue studies.

\subsection{ORDERING ELASTIC PROPERTIES BY INCREASING INFLUENCE}

In accordance with the previous results, generally speaking, it could be said that the highest influences were found for the longitudinal stiffness and the lateral stiffness of the primary suspension, and the lowest influences for the vertical stiffness and the vertical damping of the primary suspension, with the parameters of the secondary suspension showing intermediate influences between them.

Finally, the elastic properties of the vehicle were grouped considering the operating conditions under which their value could be estimated with a lesser degree of accuracy for future simulations, without significantly affecting the simulation results:

- d1Z: for any condition.

- $\mathrm{k1Z}, \mathrm{d} 2 \mathrm{Z}$ : for almost any condition, except for some ride quality indexes.

- $\mathrm{k} 1 \mathrm{Y}, \mathrm{k2Z}, \mathrm{d} 2 \mathrm{Y}$ : just for some particular combinations of study, track layout and speed.

- $\mathrm{k} 1 \mathrm{X}, \mathrm{k} 2 \mathrm{Y}$ : for no condition.

However, as already seen, those conditions in which it is admissible to assess the numerical value of a given parameter differ according to the study to be performed: safety, track fatigue or ride quality. Consequently, the value of the above parameters could be estimated with a lesser degree of accuracy for some other operating conditions. 


\section{CONCLUDING REMARKS}

In this work, the influence of the elastic properties of the primary and secondary suspensions was analyzed to assess their impact on the vehicle's dynamic behavior. As a whole, 8 different elastic properties were considered:

- longitudinal, lateral and vertical stiffness of the primary suspension;

- lateral and vertical stiffness of the secondary suspension;

- vertical damping of the primary suspension;

- lateral and vertical damping of the secondary suspension.

Due to the great number of uncertain parameters and external conditions (vehicle speed and track layout) to be considered, a simple approach, consisting in modifying the input parameters one at a time, was chosen to perform this study.

To undertake the study, a reference value, extracted from the railway vehicles database RVDynDB, was considered for each elastic property, thus defining an initial point in the space of input parameters:

Two additional values were assigned to each parameter, corresponding to the percentiles 10 and 90 of the data set stored in the vehicles database, hence exploring the 8-dimensional space by looking to both a lower and an upper value in each direction. These represent just $2 \cdot 8=16$ vertices of a hypercube with $2^{8}=256$ vertices.

From these figures, it can be seen that the number of cases possible to test was necessary limited, thus conditioning the simplicity of the methodology to be used. This way, the study was focused on passenger vehicles with linear suspension models, and the input parameters were modified one at a time, with just three values in each variation, even for parameters with large variation ranges, so assuming that the output quantities are smooth functions of the input parameters. Therefore, as previously stated, the conclusions that can be drawn are also limited from a quantitative point of view, but they can provide a qualitative idea about which influence quantities need to be addressed with particular care when performing simulations addressing a specific problem.

After processing the results of the simulations, the elastic properties of the vehicle suspension were ordered by increasing influence. It was concluded that the highest influences were found for the longitudinal stiffness and the lateral stiffness of the primary suspension, and the lowest influences for the vertical stiffness and the vertical damping of the primary suspension, with the parameters of the secondary suspension showing intermediate influences between them.

The elastic properties of the vehicle suspensions were also grouped considering the operating conditions under which their value could be estimated with a lesser degree of accuracy for future simulations, without significantly affecting the simulation results:

- $\mathrm{d} 1 \mathrm{Z}$ : for any condition.

- $\mathrm{k1Z}, \mathrm{d} 2 \mathrm{Z}$ : for almost any condition, except for some ride quality indexes.

- $\mathrm{k} 1 \mathrm{Y}, \mathrm{k2Z}, \mathrm{d} 2 \mathrm{Y}$ : just for some particular combinations of study, track layout and speed.

- $\mathrm{k} 1 \mathrm{X}, \mathrm{k} 2 \mathrm{Y}$ : for no condition.

Though it was not considered in this analysis, it should be pointed out that, in fact, some elastic parameters are interconnected to each other. So, if certain stiffness is well known, some other suspension characteristics would have a lower initial uncertainty. Nevertheless, the results found in this study could be useful when not all the data required to undertake a future simulation job are initially known, and there are no possibilities of testing. Such 
situations may arise, for instance, when the components to be modelled were manufactured by third parties or even when the vehicle to be analyzed was manufactured many years ago, as sometimes happens when dealing with derailment reconstructions. In such situations, the previous results could help to decide whether to accept or not any possible request to undertake a dynamic analysis for a vehicle with some unknown parameters.

Further development of the work proposed here might consist in varying the parameters found to be most important in smaller steps or, even further, in undertaking a probabilistic approach to consider simultaneous variations of the uncertain input parameters. In fact, from the results obtained, the number of parameters to be considered to undertake such probabilistic approach could be reduced. This way, quantitative and more accurate results could be obtained with a considerable lower computational cost than considering all the uncertain input parameters.

\section{REFERENCES}

1. Suarez, Berta. Metodología Analitica para el Estudio de Sensibilidades Aplicado a Modelos de Simulación Dinámica de Vehículos Ferroviarios, desde el Punto de Vista de la Seguridad, la Fatiga de Vía y la Calidad de Marcha. Madrid : Sección de Publicaciones de la Escuela Técnica Superior de Ingenieros Industriales, 2010. 978-84-693-2329-8.

2. Suarez, B., Felez, J. y Maroto, J. Sensitivity analysis to assess the impact of the inertial properties of railway vehicle bodies on the vehicle's dynamic behaviour. Vehicle System Dynamics. under review.

3. Suarez, B., Felez, J. y Lozano, J.A. Sensitivity analysis to assess the impact of the rolling properties of railway vehicles on the vehicle's dynamic behaviour. Suarez, B.; Felez, J.; Lozano, J.A.; Rodriguez, P., in preparation.

4. Mazzola, Laura y Bruni, Stefano. Effect of suspension parameter uncertainty on the dynamic behaviour of railway vehicles. Applied Mechanics and Materials. 2012, Vol. 104, págs. 177-185.

5. Sandu, Adrian, Sandu, Corina y Ahmadian, Mehdi. Modeling multibody systems with uncertainties. Part I: Theoretical and computational aspects. Multibody System Dynamics. 2006, Vol. 15, págs. 373-395.

6. Orlova, Anna y Boronenko, Yuri. The Anatomy of Railway Vehicle Running Gear. [ed.] Simon Iwnicki. Handbook of Railway Vehicle Dynamics. Boca Raton : CRC Press, 2006, 3, págs. 1-552.

7. Suarez, B., Felez, J. y Sanz, J.D. Proposal of a Reference Model for Dynamic Sensitivity Analysis of Long-Distance Railway Passenger Cars. Probabilistic Engineering Mechanics. under review.

8. - XML-based language for data exchange of rail vehicle dynamic simulation models. Vehicle System Dynamics. under review.

9. UIC. UIC-518, Testing and Approval of Railway Vehicles from the Point of View of their Dynamic Behaviour - Safety - Track Fatigue - Ride Quality. 2003.

10. CEN. EN 14363, Aplicaciones Ferroviarias - Ensayos para la Aceptación del Comportamiento Dinámico de los Vehículos Ferroviarios - Ensayos en Línea y en Parada. 2007.

11. Polach, Oldrich, Berg, Mats y Iwnicki, Simon. Simulation. [aut. libro] Simon (ed.) Iwnicki. Handbook of Railway Vehicle Dynamics. Boca Raton : CRC, 2006, 12.

12. Evans, Jerry y Berg, Mats. Challenges in simulation of rail vehicle dynamics. Vehicle System Dynamics. 2009, Vol. 47, págs. 1023-1048. 
13. Bruni, Stefano, y otros. Modelling of suspension components in a rail vehicle dynamics context. Vehicle System Dynamics (Special issue: state of the art papers of the 22nd IAVSD symposium). 2011, Vol. 49, págs. 1021-1072.

14. Berg, Mats. A three-dimensional airspring model with friction and orifice damping. Vehicle system dynamics supplement. 1999, Vol. 33, págs. 528-539.

15. Shimozawa, Kazuyuki y Tohtake, Takayuki. An air spring model with non-linear damping for vertical motion. QR of RTRI. 2008, Vol. 49, págs. 209-214.

16. Sayyaadi, H. y N.Shokouhi. A new model in rail-vehicles dynamics considering nonlinear suspension components behavior. International Journal of Mechanical Sciences. 2009, Vol. 51, págs. 222-232.

17. Alonso, A., y otros. Air suspension characterisation and effectiveness of a variable area orifice. Vehicle System Dynamics Supplement. 2010, Vol. 48, págs. 271-286.

18. Berg, Mats. A model for rubber springs in the dynamic analysis of rail vehicles. Proceedings of the Institution of Mechanical Engineers - Part F - Journal of Rail \& Rapid Transit. 1997, Vol. 211, págs. 95-108.

19. - . A non-linear rubber spring model for rail vehicles dynamics analysys. Vehicle System Dynamics. 1998, Vol. 30, págs. 197-212.

20. Jönsson, P. A., Andersson, E. y Stichel, S. Influence of Link Suspension Characteristics Variation on Two-Axle Freight Wagon Dynamics. Vehicle System Dynamics Supplement. 2006, Vol. 44, págs. 415-423.

21. Jönsson, P.A., Stichel, S. y Persson, I. New simulation model for freight wagons with UIC link suspension. Vehcicle System Dynamics Supplement. 2008, Vol. 46, págs. 695-704.

22. Analysis and Experiment for Improvement of Running Stability and Curving Performance of Bogie. Adachi, M. [ed.] I. Zobory. Budapest (Hungary) : s.n., 2004. Proceedings of the 6th International Conference on Railway Bogies and Running Gears. págs. 217-226.

23. Improvement in Secondary Suspension of "IRY-IR2O" Coach using ADAMS/Rail. Arvind, Khare, y otros. Haarlem (The Netherlands) : s.n., 2000. 5th ADAMS/Rail Users' Conference.

24. Claus, H. y Schiehlen, W. Stability Analysis of Railways with Radialelastic Wheelsets. Vehicle System Dynamics Supplement. 2002, Vol. 37, págs. 453-464.

25. Dukkipati, Rao.v. Vehicle Dynamics. s.1. : Alpha Science International, Ltd, 2000. 1842650149.

26. Dukkipati, Rao V. y Swamy, S. Narayana. Lateral Stability and Steady State Curving Performance of Unconventional Rail Trucks. Mechanism and Machine Theory. 2001, Vol. 36, págs. 577-587.

27. - . Non-linear Steady-State Curving Analysis of some Unconventional Rail Trucks. Mechanism and Machine Theory. 2001, Vol. 36, págs. 507-521.

28. Garg, V. K. y Dukkipati, R. V. Dynamics of Railway Vehicle Systems. s.1. : Academic Press, 1984. 0122759508.

29. Giménez, José Germán. Estabilidad en Dinámica Ferroviaria. II Curso de Especialización en Tecnologias Ferroviarias. Madrid : CITEF, 2001.

30. He, Yuping y Mcphee, John. Multidisciplinary Optimization of Multibody Systems with Application to the Design of Rail Vehicles. Multibody System Dynamics. 2005, Vol. 14, págs. 111-135.

31. Knothe, Klaus y Stichel, Sebastian. Schienenfahrzeugdynamik. s.1. : Springer Verlag, 2003. 3-540-43429-1. 
32. Lee, Sen-Yung y Cheng, Yung-Chang. Hunting Stability Analysis of High-Speed Railway Vehicle Trucks on Tangent Tracks. Journal of Sound and Vibration. 2005, Vol. 282, págs. 881-898.

33. Dynamic Analysis of a New Double Deck Passenger Vehicle with Bogie PW200. Lu, Zhenggang y Hecht, Markus. Utrecht (The Netherlands) : s.n., 1999. 4th ADAMS/Rail Users' Conference.

34. A Method to Reduce Dynamic Lateral Force between Wheel and Rail Caused by Lateral Irregularity. Miyajima, Ayumu, y otros.

35. La Evolución de los Bogies. Nouvion, F. [ed.] Asociación de Investigación del Transporte. Madrid : s.n., 1977. Simposio sobre Dinámica Ferroviaria. págs. 125209.

36. Panagin, Romano. La Dinamica del Veicolo Ferroviario. Torino : Editrice Universitaria Levrotto \& Bella, 1997.

37. Polach, O. Coupled Single-Axle Running Gears-A New Radial Steering Design. Journal of Rail and Rapid Transit. 2002, Vol. 216, págs. 197-206.

38. Santamaria, Javier y Vadillo, Ernesto G. Equivalent Conicity and Curve Radius Influence on Dynamical Performance of Unconventional Bogies. Comparison Analysis. Vehicle System Dynamics Supplemeni. 2004, Vol. 41, págs. 133-142.

39. Modelos de Cálculo de la Dinámica de los Vehículos. Sauvage, G. [ed.] Asociación de Investigación del Transporte. Madrid : s.n., 1977. Simposio sobre Dinámica Ferroviaria. págs. 61-123.

40. ShuGuang, Zhang, WeiHua, Zhang y XueSong, Jin. Dynamics of High Speed Wheel/Rail System and its Modelling. Chinese Science Bulletin. 2007, Vol. 52, págs. 1566-1575.

41. Yabuno, H., Okamoto, T. y Aoshima, N. Effect of Lateral Linear Stiffness on Nonlinear Characteristics of Hunting Motion of a Railway Wheelset. Meccanica. 2002, Vol. 37, págs. 555-568.

42. Adachi, Masahito. Analysis of The Improvement of Running Performance by Secondary Suspension. Vehicle System Dynamics Supplement. 2004, Vol. 41, págs. $754-763$.

43. Ahmadian, Mehdi y Yang, Shaopu. Effect of System Nonlinearities on Locomotive Bogie Hunting Stability. Vehicle System Dynamics. 1998, Vol. 29, págs. 365-384.

44. Allen, P. D. y Iwnicki, S. D. The Critical Speed of a Railway Vehicle on a Roller Rig. Journal of Rail and Rapid Transit. 2001, Vol. 215, págs. 55-64.

45. Influence of Bogie to Car Body Connection Parameters on Stability and Curving of Freight Vehicles. Boronenko, Yu. P. y Orlova, S. M. [ed.] I. Zovory. Budapest (Hungary) : s.n., 2004. Proceedings of the 6th International Conference on Railway Bogies and Running Gears. págs. 67-72.

46. Bosso, N., Gugliotta, A. y Somà, A. Simulation of Narrow Gauge Railway Vehicles and Experimental Validation by mean of Scaled Tests on Roller Rig. Meccanica. 2008, Vol. 43, págs. 211-223.

47. Braghin, Francesco, Bruni, Stefano y Resta, Ferruccio. Active Yaw Damper for the Improvement of Railway Vehicle Stability and Curving Performances: Simulations and Experimental Results. Vehicle System Dynamics. 2006, Vol. 44, págs. 857-869.

48. Lorenzo, Michael de. NUCARS Modeling of a Freight Locomotive with Steerable Trucks. Virginia Polytechnic Institute and State University. 1997. Tesis.

49. Mohan, Anant. Nonlinear Investigation of the Use of Controllable Primary Suspensions to Improve Hunting in Railway Vehicles. Virginia Polytechnic Institute and State University. 2003. 
50. Molatefi, H., Hecht, M. y Kadivar, M. H. Critical Speed and Limit Cycles in the Empty Y25-Freight Wagon. Journal of Rail and Rapid Transit. 2006, Vol. 220, págs. 347-359.

51. - . Effect of Suspension System in the Lateral Stability of Railway Freight Trucks. Journal of Rail and Rapid Transit. 2007, Vol. 221, págs. 399-407.

52. Polach, O. Curving and Stability Optimisation of Locomotive Bogies using Interconnected Wheelsets. Vehicle System Dynamics Supplement. 2004, Vol. 41, págs. 53-62.

53. Wickens, Alan. H. Fundamentals of Rail Vehicle Dynamics: Guidance and Stability. s.1. : Swets \& Zeitlinger, 2003. 90-265-1946-X.

54. Analysis of Hopf Bifurcation in Rail Vehicle Dynamics. Yang, Shaopu y Ahmadian, Mehdi. Copenhagen (Denmark) : s.n., 1999. Proceedings of the Third European Nonlinear Oscillations Conference (ENOC).

55. Zboinski, Krzysztof. Dynamical Investigation of Railway Vehicles on a Curved Track. Eur. J. Mech. A/Solids. 1998, Vol. 17, págs. 1001-1020.

56. Zboinski, Krzysztof y Dusza, Miroslaw. Analysis and Method of the Analysis of Non-Linear Lateral Stability of Railway Vehicles in Curved Track. Vehicle Sysiem Dynamics Supplement. 2004, Vol. 41, págs. 222-231.

57. Zboinski, K. y Dusza, M. Development of the Method and Analysis for Non-Linear Lateral Stability of Railway Vehicles in a Curved Track. Vehicle System Dynamics Supplement. 2006, Vol. 44, págs. 147-157.

58. Zhang, Weihua, y otros. Roller Rigs. [ed.] Simon Iwnicki. Handbook of Railway Vehicle Dynamics. Boca Raton : CRC Press, 2006, 14, págs. 457-506.

59. Mazzola, Laura y Bruni, Stefano. Effect of suspension parameter uncertainty on the dynamic behaviour of railway vehicles. Applied Mechanics and Materials. 2012, Vol. 104, págs. 177-185.

60. Brabie, Dan. On the Influence of Rail Vehicle Parameters on the Derailment Process and its Consequences. Royal Institute of Technology. Stockholm (Sweden) : s.n., 2005.

61. He, Yuping y Mcphee, John. Optimization of Curving Performance of Rail Vehicles. Vehicle System Dynamics. 2005, Vol. 43, págs. 895-923.

62. Dukkipati, R. V. y Dong, R. Idealized Steady State Interaction between Railway Vehicle and Track. 1999, Vol. 213, págs. 15-29.

63. Yang, Y. B., Yau, J. D. y Wu, Y. S. Vehicle-Bridge Interaction Dynamics. Singapore : World Scientific Publishing, 2004. 981-238-847-8.

64. Datoussaid, Selim, Verlinden, Olivier y Conti, Calogero. Application of Evolutionary Strategies to Optimal Design of Multibody Systems. Multibody System Dynamics. 2002, Vol. 8, págs. 393-408.

65. Diedrichs, B., y otros. Vehicle Dynamics of a High-Speed Passenger Car due to Aerodynamics Inside Tunnels. Journal of Rail and Rapid Transit. 2007, Vol. 221, págs. 527-545.

66. Dukkipati, R. V. y Amyot, J. R. Computer-aided Simulation in Railway Dynamics. s.1. : Marcel Dekker (Mechanical Engineering), 1987. 0824777875.

67. Comfort study of railcar A-TER X 73500 - Simulation with ADAMS/Rail. Geoffroy, Pascal y D'Ortona, Fabrice. Utrecht (The Netherlands) : s.n., 1999. 4th ADAMS/Rail Users' Conference.

68. Kargarnovin, M. H., y otros. Ride Comfort of High-Speed Trains Travelling over Railway Bridges. Vehicle System Dynamics. 2005, Vol. 43, págs. 173-199.

69. Mastinu, G. R. M., Gobbi, M. y Pace, G. D. Analytical Formulae for the Design of a Railway Vehicle Suspension System. Proceedings of the Institution of Mechanical Engineers: Part C. 2001, Vol. 215, págs. 683-698. 
70. Marcha Sinusoidal y Oscilaciones de Flexión Transversal, en Cajas de Automotores Circulando a Altas Velocidades. Mohacsi, s. [ed.] Asociación de Investigación del Transporte. Madrid : s.n., 1977. Simposio sobre Dinámica Ferroviaria. págs. 213234.

71. Iwnicki, Simon. The Manchester benchmark for rail vehicle simulation. Vehicle System Dynamics. 1999, Vol. 31 (Suppl.), págs. 1-48.

72. European Railway Research Institute - ERRI B 176/DT 290. $B$ 176/3 Benchmark Problem: Results and Assessment. Utrecht : s.n., 1993.

73. VOLPE Center. John A. Volpe National Transportation Systems Center. $L D$ Benchmark. [En línea] 2005.

http://www.volpe.dot.gov/coi/pis/work/archive/docs/ldbenchmark/report.pdf.

74. Suarez, B., Sanz, J.D. y Felez, J. Hierarchical classification of railway vehicles by the application of taxonomic analysis techniques. Probabilistic Engineering Mechanics. under review. 